\title{
A SLIP-LINE FIELD ANALYSIS OF THE DEFORMATION AT THE CONFLUENGE OF TWO GLACIER STREAMS
}

\author{
By I. F. Collins \\ (Department of Mathematics, University of Manchester Institute of Science and Technology, \\ Manchester, England)
}

\begin{abstract}
The deformation and state of stress at the confluence of two glacier streams are analysed using the techniques of slip-line theory. The valley walls are taken to be vertical parallel planes and the deformation is supposed independent of depth. The mechanical behaviour of ice is modelled by the ideal rigid/perfectly
plastic material.

Detailed solutions are presented for the deformation at the confluence of one or more tributaries with a main stream and of two main streams. Attention is concentrated on predicting the number, position and magnitude of the bands of intense shear which emanate from some of the junction corners. The predictions of this idealized theory are compared with field data from a confluence on the Kaskawulsh Glacier, Yukon
Territory, Canada.

RÉsumé. Une analyse par la méthode des lignes de glissement de la déformation a: confluent de deux courants glaciaires. La déformation et l'état des contraintes au confluent de deux courants de glace sont analysés par la méthode de la théorie des lignes de glissement. Les berges du lit glaciaire sont assimilées à des plans verticaux parallèles et la déformation est supposée indépendante de la profondeur. Le comportement mécanique de la glace est simulé par celui d'un matériau idéalement rigide/parfaitement plastique.

Des solutions détaillées sont proposées pour la déformation au confluent d'un ou plusieurs affluents avec un ou deux courants principaux. On s'attache particulièrement à prévoir le nombre, la position et l'importance des bandes de cisaillement intense qui se produisent à certains points de jonction. Les prévisions de la théorie sont confrontées avec les données recueillies à une confluence du Kaskawulsh Glacier, Territoire du
Yukon, Canada.

Zusammenfassung. Eine Analyse der Deformation am Zusammenfluss zweier Gletscherströme aus dem Gleitlinienfeld. Die Deformation und der Spannungszustand am Zusammenfluss zweier Gletscherströme wird mit Hilfe der Gleitlinientheorie analysiert. Die Talwände werden als vertikale Parallelebenen, die Deformation als tiefenunabhängig angenommen. Das mechanische Verhalten des Eises wird aus der Modellvorstellung eines ideal starrfesten, vollkommen plastischen Materials abgeleitet.

Für die Deformation am Zusammenfluss eines oder mehrerer Nebenströme mit einem Hauptstrom sowie von zwei Haupströmen werden detaillierte Lösungen angegeben. Besondere Aufmerksamkeit wird auf die Voraussage der Anzahl, Lage und Grösse der Bänder mit intensiver Scherung gerichtet, welche von einigen der Schnittpunkte beim Zusammenfluss ausgehen. Die Voraussagen aus dieser idealisierten Theorie werden mit Feldbeobachtungen von einem Zusammenfluss am Kaskawulsh-Gletscher im Yukon Territory, Canada,
verglichen.
\end{abstract}

\section{Introduction}

This paper presents a theoretical analysis of the deformation and stress fields at the junction of two glacier streams. The only previous attempt at such an analysis is that of Sharp (1948), who however based his arguments on the erroneous "extrusion flow" hypothesis. There have, however, been a large number of isolated field measurements of surface velocities, strain-rates etc. in confluence zones on a number of glaciers, and recently a very comprehensive study of a confluence on the Kaskawulsh Glacier, Yukon Territory, Canada has been made by Anderton (unpublished).

Any analysis of the deformation at an actual confluence would be most complicated due to the complex irregular geometry of the valley walls. Consequently to make any progress it is necessary to idealize the geometry of the situation quite appreciably. Further, as will be seen below, to make the problem tractable it is necessary to approximate the mechanical behaviour of ice by that of a rigid/perfectly-plastic material. Thus, one cannot hope to obtain any detailed quantitative agreement between such an idealized mathematical model and a specific set of field data. Instead attention is concentrated on investigating the qualitative features of the deformation and stress fields and their dependence on the defining parameters. It is hoped that the results presented here will form a basis for discussing the morphology of confluences such as crevasse and foliation patterns. 
The valley walls will be assumed to be parallel and vertical and the deformation is assumed to be in plane strain, so that the deformation pattern is independent of the depth below the surface. In view of these restrictions the "inset" and "overlaid" conditions (Sharp, 1948) fall outside the scope of this theory. Some indication of the way in which this simple twodimensional picture must be modified to meet the actual three-dimensional situation will come out in the analysis. It is shown that the flow planes which here are assumed to be parallel to a flat inclined bed will in fact, become twisted at a confluence due to a secondary flow (Fig. 23).

The mechanical model which best fits the experimental data on ice is the power-law creep relation between stress and strain-rate (Glen's law). Boundary-value problems involving these creep equations are extremely complex and difficult to solve in two- or threedimensional situations. Consequently, with one exception (Nye, 1957), all glacier flow theories using these equations are one-dimensional. However, one can make progress with two-dimensional problems if one lets the exponent in Glen's law $n$ ( $\approx 3$ or 4 ) tend to infinity. In the limit Glen's equations go over to those for a rigid/perfectly-plastic material with a Mises yield criterion (Nye, I953). Such a material behaves rigidly as long as $\tau<k$ where $\tau$ is the "effective shear stress" and $k$ is a material constant. When $\tau=k$ the material deforms at an indefinite rate but in such a way that the components of the strain-rate and stress-deviator tensors are proportional. The condition $\tau>k$ cannot occur. This approximation was first used by Nye (I 95I) when he modelled a glacier by a two-dimensional block of rigid/perfectly plastic material resting on an inclined plane. More recently the same approximation has been

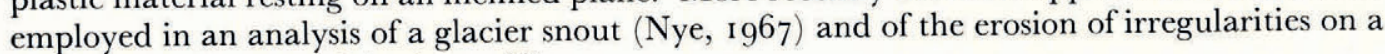
glacier bed (Nye and Martin, I968).

Above and below the confluence zone the ice is assumed to move rigidly as in "plug flow". This is a particularly good approximation in the equilibrium-line region where the longitudinal strain-rates are small. The deformation is hence localized to a definite zone. Mathematically this is a consequence of the hyperbolic nature of the governing equations for rigid/ perfectly-plastic materials under plane strain conditions. The corresponding creep equations are elliptic (Berg, 1967), so that in a creep model the deformation caused by the merging of two ice streams would not be confined to a specific zone but would extend an indefinite distance up each arm of the glacier. The presence of a definite deformation zone in the plastic model is a distinct theoretical advantage, making the problem much more readily tractable.

The actual deformation in this zone will take two forms:

(a) discontinuities in tangential velocity across certain curves (slip lines), which on a real glacier correspond to narrow bands of intense shear. Such bands are frequently observed in the confluence zones of temperate glaciers and show up particularly well in air photographs where they may be seen to cause kinks in longitudinal structures and moraines.

(b) regions of continuous deformation in which the strain-rates are finite.

One of the prime objectives of this investigation is to find the number, position and strength of these velocity discontinuities (shear bands). As will be seen these factors depend critically on the overall geometry of the junction and on the relative velocities of the two converging streams.

To complete the posing of the problem, it is necessary to specify some boundary conditions on the valley walls. The normal component of velocity must, of course, be zero. The other required condition is some frictional law on the tractions. There would still appear to be some considerable doubt about what this law should be. The approach adopted here is to produce solutions for two extreme conditions, perfectly lubricated (no shear stress) and perfectly rough walls (shear stress $=k$, the yield stress), and to compare and contrast the corresponding deformation patterns. Most surface strain-rate measurements such as those reported by 
Meier (1960) from the Saskatchewan Glacier and by Anderton (unpublished), would indicate that the valley wall is close to being a maximum shear stress trajectory so that the latter is probably the more correct assumption. This is indeed the condition employed by Nye (1967) and Nye and Martin ( I968) with reference to the bed of the glacier. As will be seen, however, several of the solutions are the same under both frictional conditions.

The basic properties of solutions to plane-strain rigid/perfectly-plastic problems are reviewed in the next section in terms of slip-line fields and the hodograph diagram. In section 3 solutions are presented for configurations in which a tributary enters at the side of a main stream. Several types of solutions are required to cover the range of all possible geometric and kinematic conditions. The specific form of solution valid for a particular confluence can be read off from one of two nomographs. The possibility of interference between the two deformation zones when two tributaries enter a main stream in close proximity is examined in section 4 , whilst solutions for the confluence of two main streams ( $\mathbf{Y}$-junction) is considered in the final section. In addition the field data obtained by Anderton on the Kaskawulsh Glacier are compared with a theoretical solution.

\section{Slip-Line fieldS AND The hodograph Diagram}

The state of stress in a plane-strain deformation of a rigid/perfectly-plastic material is most conveniently discussed in terms of "slip-line fields". For a full account of the theory the reader is referred to one of the standard texts such as Hill (1950), Prager and Hodge (I 95 I), Prager (1959), Johnson and Mellor (1962) or Ford and Alexander (1963). Slip-lines are the trajectories of maximum shear stress (and also maximum shear strain-rate) and consist of two families of mutually orthogonal curves. The two families are labelled $\alpha$ - or $\beta$-curves, chosen so that the maximum principal stress lies in the first and third quadrant of the $(\alpha, \beta)$ coordinate system (we adopt the convention used in metal plasticity of regarding tensile stresses as positive). Since the directions in which the shear stress is a maximum make angles of $45^{\circ}$ with the principal directions, it follows that the principal directions at any point bisect the slip-line directions.

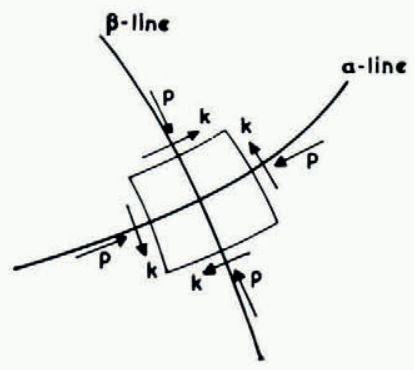

Fig. I. Stress system at a typical point in a slip-line field.

The state of stress acting on an elemental curvilinear rectangle whose sides are parallel to the slip-lines at a typical point in the plastic zone is shown in Figure $\mathrm{I}$. The stress consists of a shear stress $k$, the yield stress of the material, and an all-round hydrostatic pressure $p$. Once the value of $p$ has been obtained at one point in the network of slip-lines it can be deduced at any other point by using Hencky's relations:

$$
p+2 k \phi=\text { constant on an } \alpha \text {-line, } \quad p-2 k \phi=\text { constant on a } \beta \text {-line, }
$$

$\phi$ being the anticlockwise inclination of the $\alpha$-line to some fixed reference direction. The characterizing property of slip-line nets which distinguish them from any other set of orthogonal curves is embodied in Hencky's Theorem. This states that "the angle between two 
slip-lines of one family, where they are cut by a slip-line of the other family, is constant along their length" as illustrated in Figure 2. A system of curves having this property is frequently referred to as a "Hencky-Prandtl net".

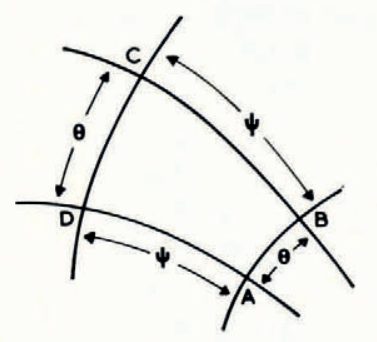

Fig. 2. The Hencky-Prandtl property of slip-line fields.

Corresponding to Equations (I) are relations which state how the velocities vary along the slip-lines. If $(u, v)$ are the components of velocity along the $\alpha$ - and $\beta$-lines respectively, then

$$
\mathrm{d} u-v \mathrm{~d} \phi=0 \text { on an } \alpha \text {-line, } \quad \mathrm{d} v+u \mathrm{~d} \phi=0 \text { on a } \beta \text {-line. }
$$

These are Geiringer's equations and can be given a most useful geometric interpretation in the velocity or "hodograph" plane. (For full details see Green (I954), Prager (I953) or the last three texts cited above). Referring to Figure 3 , we represent the velocity at a typical point $\mathrm{P}$ in the slip-line field by a vector op in the velocity plane. As P traces out an $\alpha$ - or $\beta$-slip-line in the physical plane its image $p$ traces out an $\alpha^{\prime}$ or $\beta^{\prime}$-curve in the velocity plane. It is shown in the above references that Equations (2) imply that this image curve is everywhere orthogonal to the original slip-line. Thus, in Figure 3 , the tangent to the $\alpha^{\prime}$-curve at $p$ is perpendicular to the tangent to the $\alpha$-curve at P and is, therefore, parallel to the tangent to the $\beta$-curve at $\mathrm{P}$. It follows also that the complete net of curves in the hodograph plane possess the characteristic Hencky-Prandtl property described above.

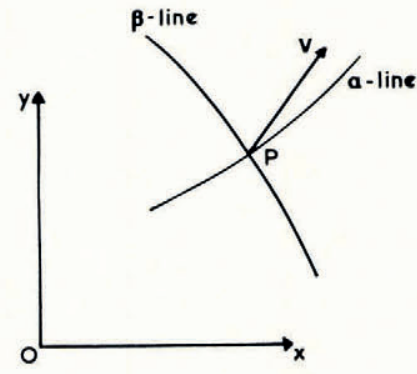

(a)

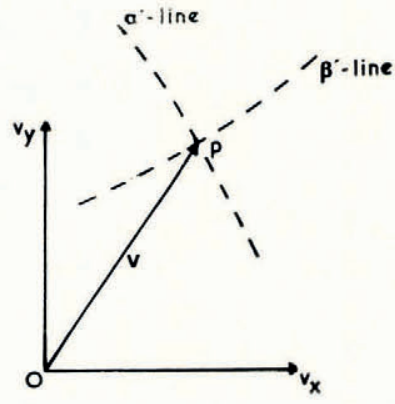

(b)

Fig. 3. Representation of velocity vector in (a) physical plane, (b) velocity or hodograph plane.

It is important to note that there can be two image curves in the hodograph plane to one slip-line. This occurs when the tangential velocity is discontinuous across a slip-line. Such a discontinuity, however, must be constant in magnitude, the two sides of the slip-line hence map into two parallel curves. It frequently happens that the material on one side of a discontinuity translates rigidly. The image of such a rigid region in the velocity plane is just a single point, and so the image of the plastic side of the dividing slip-line is a circular arc centred on this point. This construction will frequently be needed in the following. 


\section{Single tributary}

\section{(i) Statement of problem}

In this section we consider the problem of a tributary entering a main-stream (Fig. 4). To cut down the number of independent parameters we shall assume that the width of the main stream is the same above and below the confluence. The geometry will hence be completely specified, apart from scale, if we know the ratio of the main-stream width to that of the tributary entrance $(d / h)$ and the angle $\delta$ between the converging channels. If we also know the ratio of velocities in these two channels $\left(U_{1} / U_{2}\right)$ then, as will be shown, the deformation is determined provided we assume that the ice in the lower channel moves as a single rigid mass.

It has been suggested that the two ice streams might flow independently in the lower channel with different velocities. There would, therefore, be a velocity discontinuity (shear band) along the dividing stream-line. However, measurements reported by Meier (196o), Anderton (unpublished) and Allen and others (1960) indicate that although there may be intense shear in the region of the bounding stream-line immediately below the junction, this is not present further down-stream (distance of order $\frac{1}{2} h$ say). This is indeed what one might expect. Near the junction the dividing stream-line is very nearly in the direction of the maximum shear stress and hence if the dirty ice/ice interface shears more easily than the bulk of the ice, it may well do so here. Further down-stream, however, the dividing stream-line is much closer to the direction of principal stress and, therefore, not subject to any appreciable shear. In the analysis presented here the mechanical properties of the interface between the two streams are assumed to be identical with those of any other surface within the bulk of the ice. As will be seen, this theory predicts that a velocity discontinuity (shear band) will occur close to, but not coincident with, the bounding streamline just below the junction. Thus it is not clear whether the intense shear reported by Meier, Anderton, and Allen and others is due to shearing in the bulk of the ice or to slipping along the dividing stream-line.

The velocities $U_{1}$ and $U_{2}$ of the two impinging streams depend essentially on the sizes of the two accumulation basins up-stream of the confluence. These, of course, can be very different and hence the ratio $U_{\mathrm{I}} / U_{2}$ can differ significantly from unity. It will be shown that the value of this ratio is critical in determining the nature of the deformation pattern at the confluence.

The problem is hence completely specified by the three parameters $d / h, \delta$ and $U_{1} / U_{2}$. The velocity $U_{3}$ in the lower channel is determined in terms of $U_{1}$ or $U_{2}$ by the mass conservation condition:

$$
\left(U_{3}-U_{1}\right) d=U_{2} h \sin \delta .
$$

If we reverse the direction of the velocities this problem is seen to be very similar to the sideways plane-strain extrusion process (Fig. 4(c)). The solution to this, and many similar extrusion problems, may be found in the monograph by Johnson and Kudo ( 1962 ). There is, however, one important difference between the glacier confluence problem and the extrusion problem, which makes the former rather more difficult to solve. In the extrusion process the extruded billet, corresponding to the tributary, is not constrained to move in any particular direction, instead its direction is determined by the condition that it is free of any lateral force. In our problem, however, $\delta$ is specified and in general there will be a lateral pressure (to be determined), exerted by one of the valley walls on the ice stream.

\section{(ii) Basic solution for smooth walls}

The form of the slip-line solution for this problem, assuming the valley walls are perfectly smooth, is shown in Figure $4(\mathrm{a})$ and the hodograph in Figure $4(\mathrm{~b})$. The slip-line field consists of two "centred fan" regions ADE and BDF in which the slip-lines of one family are straight radial lines and of the other are circular arcs. The remainder of the field DEcF is defined uniquely as 
the field between the two circular arcs DE and DF. In Hill's (1950) nomenclature this is an example of a boundary-value problem of the first type. The hodograph net is rather similar and consists of two centred fans Ica and IIIcb of equal radii and the field defined by the two equal circular arcs ca and cb. This particular field occurs frequently in solutions to boundary value problems and may be found tabulated in Hill (1950) or Ewing (1967). The vectors or

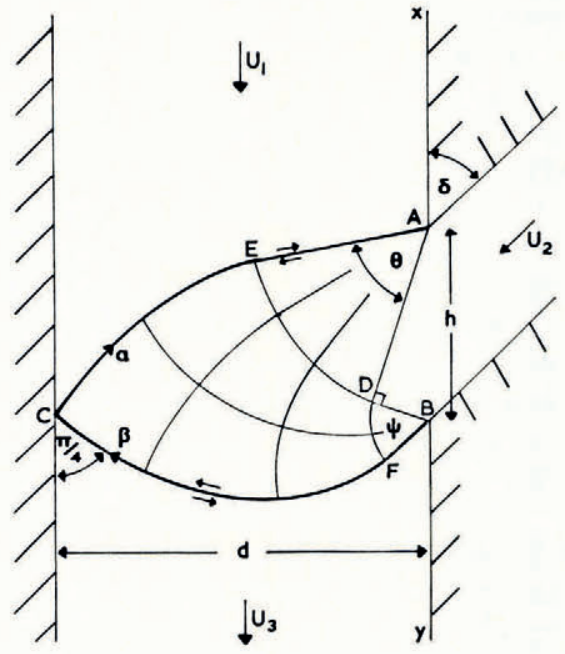

(a)

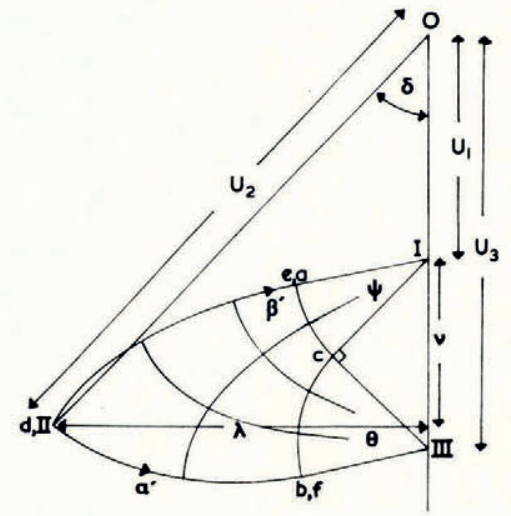

(b)

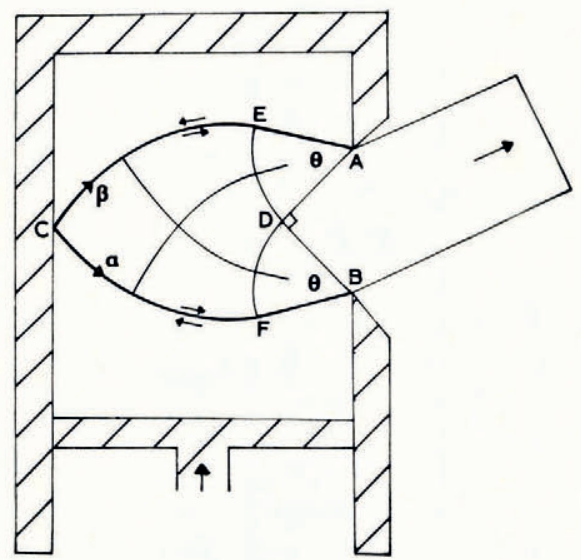

(c)

Fig. 4. Basic solution for single tributary with smooth walls $(a)$ slip-line field, $(b)$ hodograph, (c) slip-line field for sideways extrusion.

and oni represent the velocities $U_{1}$ and $U_{3}$ of the main stream above and below the confluence, and ofr represents the velocity $U_{2}$ of the tributary. Here, as elsewhere in this paper, we shall adopt the standard convention of denoting the images in the velocity plane of points in the physical plane by the appropriate lower case letter. The two centred fans in the hodograph represent the velocity discontinuity, of magnitude $\left(U_{3}-U_{1}\right) / \sqrt{ } 2$, along AEcFB. Slip-lines 
across which the velocity is discontinuous are shown as heavy lines and the direction of the tangential discontinuity indicated by small arrows (cf. AEC and сFB in Figure 4(a)).

The corresponding extrusion slip-line field (Fig. 4(c)) is a particular case of the above solution, valid when the radii of the two centred fans are equal.

The solution of Figures $4(a)$ and (b) is completely determined by the two vertex angles of the centred fans $\theta$ and $\psi$, and hence has two degrees of freedom. At first sight this solution appears not to be determinate since, as discussed above, three parameters are needed to set up the problem. This paradox is resolved by noting that the slip-line field depends only on the relative velocity of the two converging streams, and hence only on a certain combination of the parameters $U_{1} / U_{2}$ and $\delta$ and not on each separately. Thus, the fieid depends only on the position of II relative to $\mathrm{I}$, in the hodograph diagram, and not on its position relative to the origin. This can best be seen by considering the effect of superimposing a constant velocity $V$ in the main-stream direction. This, of course, has the effect of changing the inflow angle $\delta$. $U_{1}, U_{3}$ and the component of $U_{2}$ in the main-stream direction are all increased by the same amount $V$, whilst the component of the tributary velocity perpendicular to the main stream $\left(U_{2} \sin \delta\right)$ is unaltered. The mass conservation condition, Equation (3), is hence automatically satisfied, and the original slip-line field is also the solution to this new problem. In the hodograph diagram the effect of superimposing this extra velocity is to move the origin up or down the I-III axis, but to leave the actual hodograph net unaltered.

For convenience we take the length of ${ }_{I}$ III, $\left(U_{3}-U_{1}\right)$, as the unit of length in the hodograph plane. The position of II, relative to $\mathrm{I}$, is hence completely specified by the dimensionless cartesian co-ordinates $(\nu, \lambda)$ as shown in Figure $4(\mathrm{~b})$, and defined by

$$
\begin{aligned}
& \nu=\left(U_{2} \cos \delta-U_{1}\right) /\left(U_{3}-U_{1}\right), \\
& \lambda=U_{2} \sin \delta /\left(U_{3}-U_{1}\right)=d / h .
\end{aligned}
$$

The last equality in (5) follows from the mass conservation condition (3). Eliminating $U_{3}$ from Equation (3) we can also express $v$ only in terms of the three defining parameters $d / h, U_{\mathrm{1}} / U_{2}$ and $\delta$ :

$$
\nu=\left(\cot \delta-\left(U_{1} / U_{2}\right) \operatorname{cosec} \delta\right)(d / h) .
$$

$\lambda$ is a purely geometric factor depending only on the geometry of the junction but $\nu$ depends also on the relative velocity of the two converging streams.

The procedure for constructing the solution is as follows. Evaluate the parameters $\lambda$ and $\nu$ from Equation (5) and (6) for the particular confluence in question. Use the hodograph diagram, which as stated above is a well tabulated net, to evaluate the two angles $\theta$ and $\psi$. (The boundary of this net is, in fact, shown in Figure 5, it being the part marked sa.) Once we know these two angles we can construct the slip-line field using any one of the standard techniques such as the grid method (Hill, I950), the graphical procedure (Prager, I959) or the series method (Ewing, I967). (This particular field can also conveniently be constructed by a transformation technique described by Collins (1968[a], section 8).)

The hodograph net is symmetric about the line $\nu=\frac{1}{2}$ (Figs. 4 (b) and 5). When $\nu=\frac{1}{2}$, $\theta=\psi$ and $U_{2} \cos \delta=\frac{1}{2}\left(U_{1}+U_{3}\right)$ which is the extrusion situation. As $\nu$ gets greater or less than $\frac{1}{2}, U_{2} \cos \delta$ is greater or less than $\frac{1}{2}\left(U_{1}+U_{3}\right)$ from $(4), \theta$ is greater or less than $\psi$ and the deformation tends to be displaced down- or up-stream in the sense that c (Fig. 4(a)) lies below or above the mid-point of $\mathrm{AB}$. If the tributary enters at right angles to the main stream, so that $\delta=90^{\circ}$, (a $\mathbf{T}$-junction) the deformation zone will always tend to be displaced up-stream since $U_{2} \cos \delta=0<\frac{1}{2}\left(U_{1}+U_{3}\right)$.

A particular example of this field has been computed, but before discussing this we consider some other types of solution. The one considered above can be regarded as the basic solution, but it will not cover the complete range of configurations that can arise. In other words, it is not always possible to find a solution of this type corresponding to every possible combination of $\lambda$ and $\nu$. 


\section{(iii) Other solutions for smooth walls}

The above solution can break down in three ways. Consider the effect of keeping the geometric factor $\lambda$ fixed and varying $\nu$. As $\nu$ increases (or decreases) from $\frac{1}{2}$ the slip-line field becomes more and more asymmetrical until either $|\theta-\psi|=\frac{1}{4} \pi$ or one or other of $\theta$ and $\psi$ becomes a right angle. As can be seen from Figure 5, the former occurs if $0.5 \leqslant \lambda \leqslant 2.5$ and the latter if $2.5 \leqslant \lambda \leqslant 6.2$.

In the first situation, the slip-line field is as shown in Figure $6(a)$ or $6(b)$; in both cases there is a straight slip-line across the entrance $\mathrm{AB}$ to the tributary. The critical values of $(\lambda, \nu)$ for which this occurs lie on the curves $\mathrm{PQ}_{0}, \mathrm{P}^{\prime} \mathrm{Q}_{0}{ }^{\prime}$ in Figure 5 . For values of $\nu$ beyond these critical

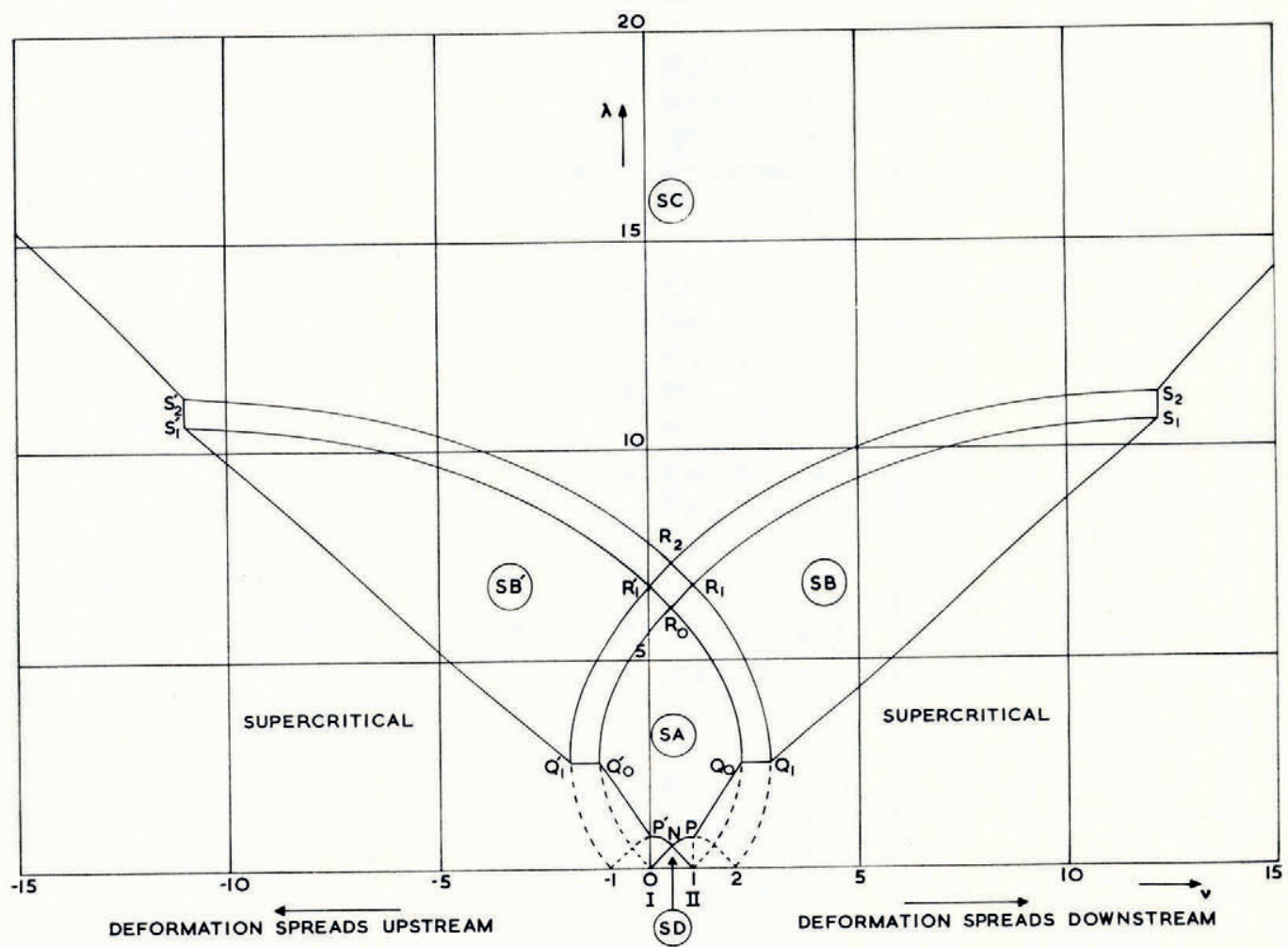

Fig. 5. Nomograph for single tributary with smooth walls. Solutions valid in regions $\mathrm{SA}, \mathrm{SB}^{\prime}$ and $\mathrm{SD}$ are shown in Figures 4,7 and 8 , respectively.

values the slip-line field is exactly the same as for the critical case (i.e. as in Fig. 6(a) or 6(b)), but an additional velocity discontinuity must be put across the slip-line $\mathrm{AB}$ at the mouth of the tributary. Typical hodographs for these supercritical solutions are shown in Figures $6(\mathrm{c})$ and $6(\mathrm{~d})$.

In the second situation when $\theta$ (or $\psi)=\frac{1}{2} \pi$, we cannot continue with the basic type of solution since the angle EÂX (or F⿱⺈⿵⺆⿻二丨冂) in Figure 4 (a) would be less than $\frac{1}{4} \pi$ and the material in this vertex, which we postulate to be rigid, would, in fact, deform plastically (this is an example of a general result due to Hill, 1954). Instead we must go over to another type of solution in which the material is plastic along part of the inner main-stream wall. Such a solution (applicable when $\nu<\frac{1}{2}$ ) is shown in Figure 7. The domains of validity of this type of solution in the $(\nu, \lambda)$ plane are marked $\mathrm{sB}\left(\nu>\frac{1}{2}\right)$ and $\mathrm{sB}^{\prime}\left(\nu<\frac{1}{2}\right)$ in Figure 5. This diagram is, in fact, just the hodograph of this new solution, which turns out to be simply an extension 
of the hodograph for the basic solution. This extended hodograph (Fig. 5) is hence a highly convenient nomograph since for given $\lambda$ and $\nu$ it enables one to read off the form of the appropriate solution, and also if plotted to a large enough scale, the angles of the relevant centred fans.

The deformation pattern differs from that previously considered in that it spreads up(down)-stream along the inner wall according as $\nu$ is less(greater) than $\frac{1}{2}$, and in that two

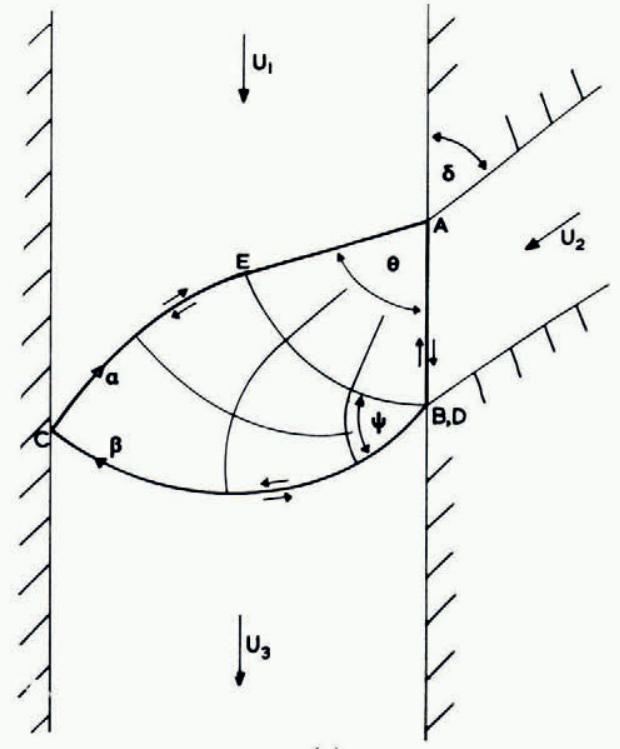

(a)

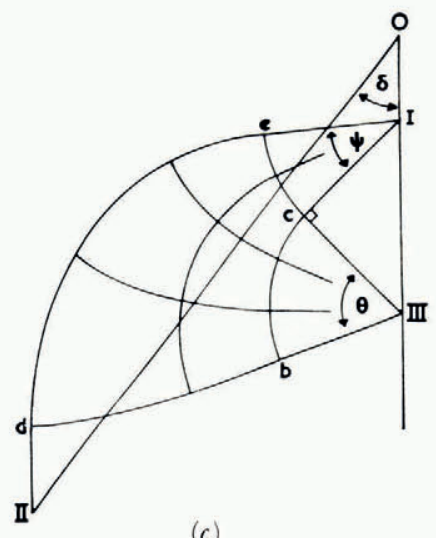

(c)

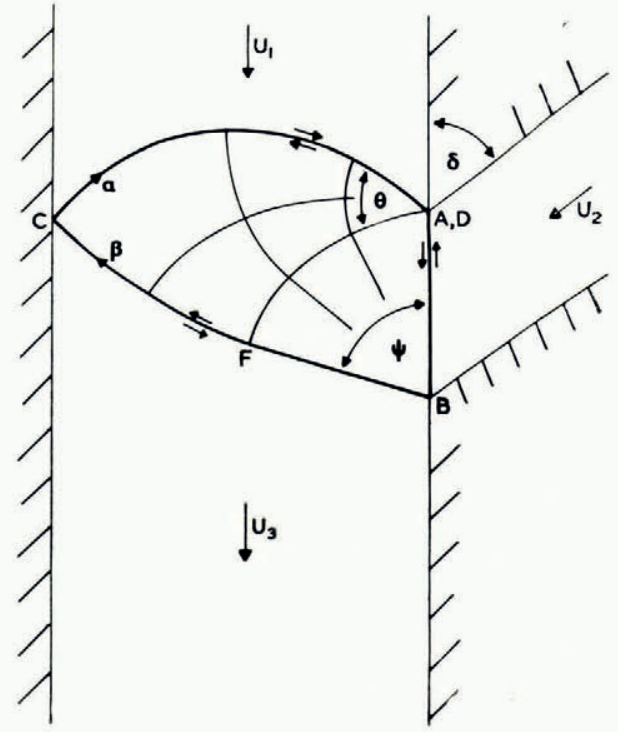

(b)

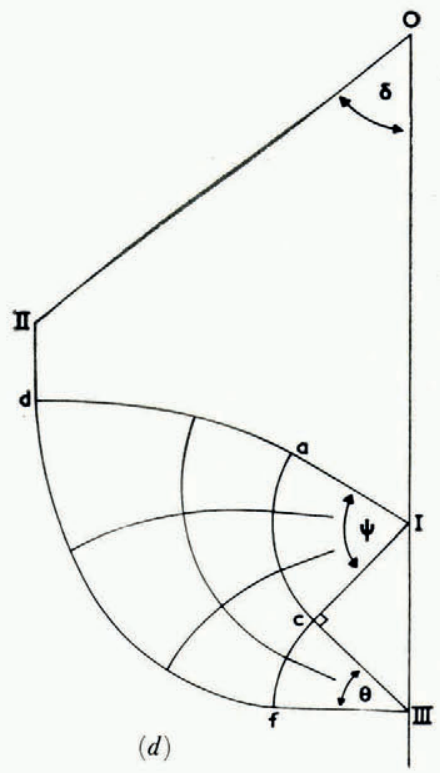

$(d)$

Fig. 6. Supercritical solutions for smooth walls and $0.5 \leqslant \lambda \leqslant 2.5 .\left(\right.$ a) slip-line field $\nu>\frac{1}{2},(b)$ slip-line field $\nu^{-}<\frac{1}{2}$, (c) hodograph $v>\frac{1}{2},(d)$ hodograph $v<\frac{1}{2}$. 


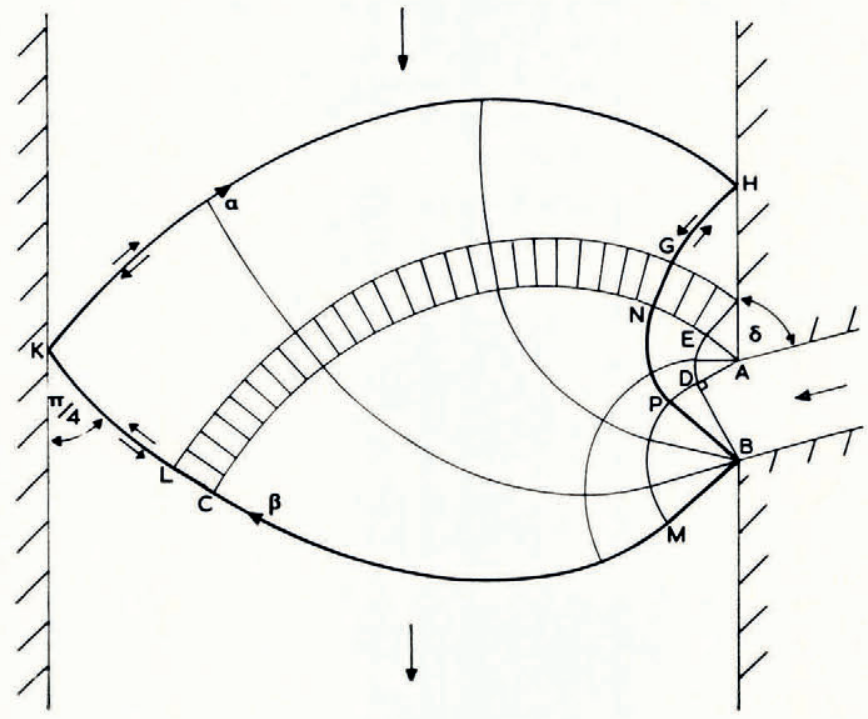

Fig. 7. Slip-line field valid in region $\mathrm{SB}^{\prime}$ in Figure 5. The corresponding field valid in $\mathrm{SB}$ is similar except that the deformation spreads down-stream along the inner main-stream wall and not up-stream.
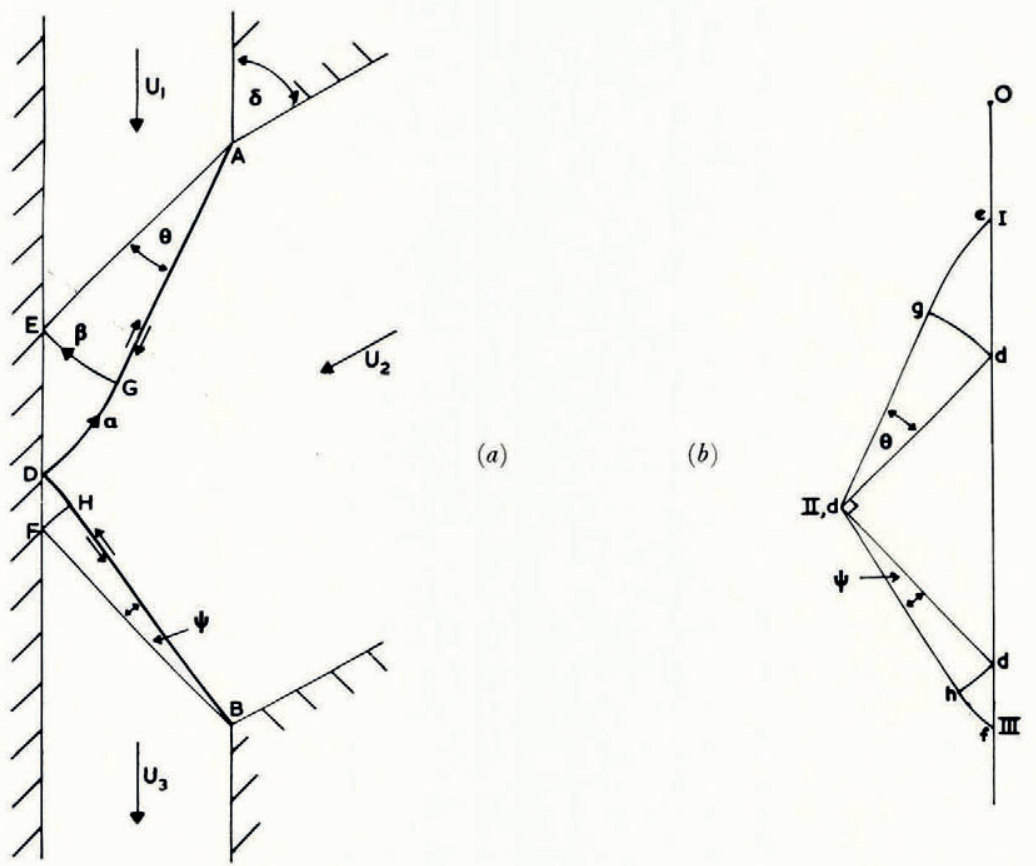

Fig. 8. (a) Slip-line field, (b) hodograph of solution valid in region SD in Figure 5. 
velocity discontinuities (shear bands) emanate from $\mathrm{B}(\mathrm{A})$ both with magnitude $\left(U_{3}-U_{\mathrm{I}}\right) / \sqrt{ } 2$. Just as for the basic one this solution breaks down when the tributary entrance AB becomes a slip-line. This happens on the curves $Q_{1} \mathrm{~s}_{1}$ and $Q_{1} \mathrm{~s}_{1}{ }^{\prime}$ in Figure 5 . For values of $|\nu|$ greater than these critical values the solution is again formed from the critical solution by adding a velocity discontinuity along the slip-line $\mathrm{AB}$.

These solutions do not apply if the $(\nu, \lambda)$ point lies above $\mathrm{R}_{I} \mathrm{~S}_{\mathrm{I}}$ or $\mathrm{R}_{\mathrm{I}}{ }^{\prime} \mathrm{s}_{\mathrm{I}}{ }^{\prime}$ in Figure 5 , in which case the deformation spreads both up- and down-stream along the inner wall of the main channel. The slip-line field is not illustrated but is a natural extension to that of Figure 7 . Its domain of validity is marked sc in Figure 5 .

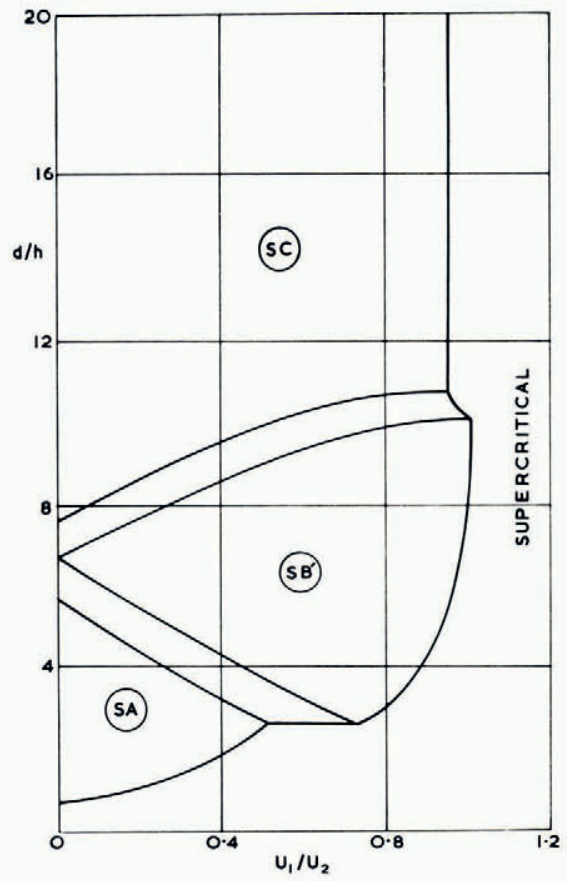

(a)

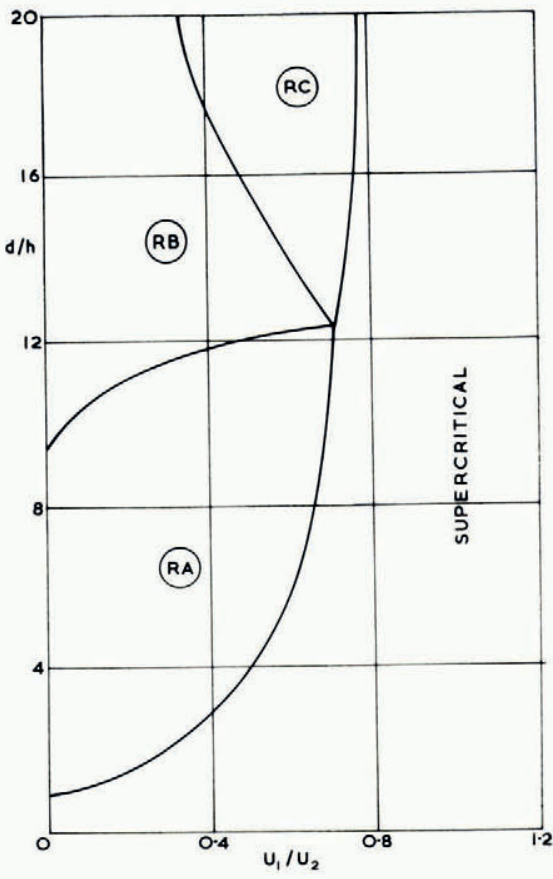

(b)

Fig. 9. Nomograph for right-angle junction (T-junction) for (a) smooth walls, (b) rough walls.

The solutions valid in the small intermediate regions between the parallel curves $Q_{0} R_{0} R_{1}{ }^{\prime} S_{1}{ }^{\prime}, Q_{1} R_{1} R_{2} S_{2}{ }^{\prime}$ and $Q^{\prime}{ }_{0} R_{0} R_{I} S_{1}, Q_{1}{ }^{\prime} R_{1}{ }^{\prime} R_{2} S_{2}$ in Figure 5 have been found in principle but are not discussed here. They are of a very much more complicated type similar to that discussed by Green (1962) and Collins (1968[b]) for extrusion.

Finally, the solution corresponding to region SD in Figure 5 is shown in Figure 8. This corresponds to values of $\lambda=d / h$ rather smaller than is met with in practice and will not be discussed in detail except to note that the magnitudes of the velocity discontinuities in this solution are rather less than $\left(U_{3}-U_{1}\right) / \sqrt{ } 2$.

It should also be noted that any of the above solutions will break down, due to overstressing of the proposed rigid regions, if the angle between the bounding slip-line and the tributary wall is less than $\frac{1}{4} \pi$. This can never happen, however, if $\delta$ lies in the range $\frac{1}{4} \pi \leqslant \delta \leqslant \frac{3}{4} \pi$. 
(iv) Right-angle junction with smooth walls

The effect of varying any of the defining parameters on the deformation can be deduced from the nomograph (Fig. 5). To be specific suppose we take $\delta=\frac{1}{2} \pi$ (a T-junction) and consider the effect of varying the geometric factor $\lambda=d / h$ and the velocity ratio $U_{1} / U_{2}$ $\left(=-\nu / \lambda\right.$ when $\left.\delta=\frac{1}{2} \pi\right)$. The zones of validity of the three basic types of solution can be shown in a $\left(d / h, U_{1} / U_{2}\right)$ diagram as in Figure $9(\mathrm{a})$. As already noted the deformation zone will always be displaced up-stream. The values of $\left(U_{1} / U_{2}\right)$ at which the solutions become supercritical and velocity discontinuities appear across the tributary mouth is seen to be approximately unity for $d / h>4$, but is rather less than unity for $d / h<4$.

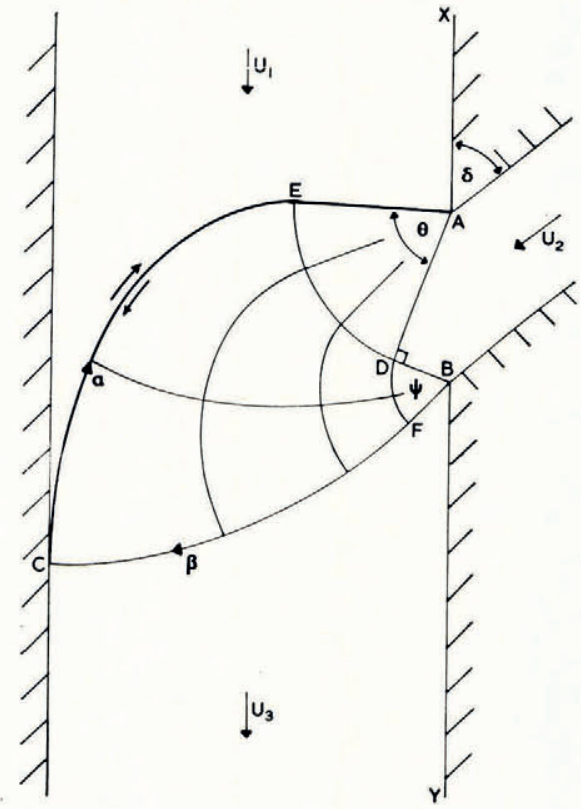

(a)

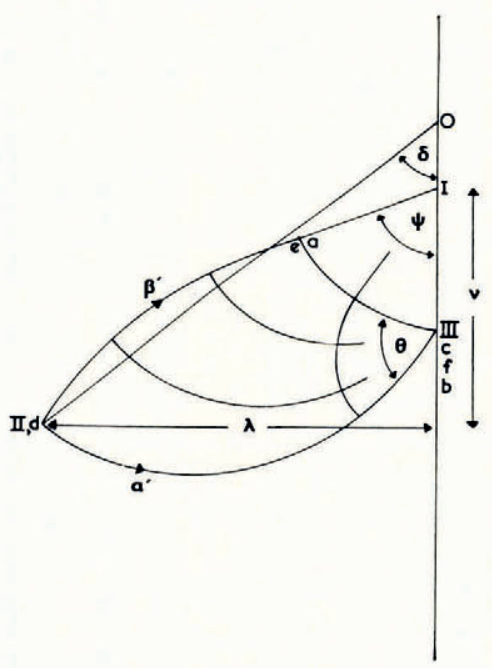

(b)

Fig. 1o. Basic solution for single tributary with rough walls $(a)$ slip-line field, $(b)$ hodograph.

\section{(v) Solutions for perfectly rough walls}

The basic solution for perfectly rough walls is shown in Figure io. It differs from that for smooth walls in that the bounding slip-lines meet the far wall tangentially and at right angles instead of at $45^{\circ}$. Also there is now only one velocity discontinuity (shear band), which emanates from the upper junction corner. Its magnitude is $\left(U_{3}-U_{\mathrm{I}}\right)$ and is hence $\sqrt{ } 2$ times stronger than the corresponding discontinuity in the smooth-wall solution. Just as before, the angles $\theta$ and $\psi$ must be chosen so that $\lambda$ and $\nu$ take the prescribed values, and again, just as before, we can use the hodograph diagram as a nomograph for this purpose. This is shown in Figure I I, the zone of validity of the present solution being RA. This field is in fact part of the singular Hencky-Prandtl net constructed on the convex side of the circular arc III NM. Unlike Figure 5, the corresponding diagram for smooth walls, this nomograph is asymmetrical about $v=\frac{1}{2}$. In addition the deformation zone will always tend to be displaced down-stream of the midpoint of $\mathrm{AB}$. 
The basic solution will break down when $\psi-\theta=0$ or $\frac{1}{2} \pi$, for in either case the tributary mouth $\mathrm{AB}$ has become a slip-line. This happens on the curves III $\mathrm{P}$ and $\mathrm{NQ}$ respectively in Figure II. For values of $\nu$ outside these ranges the solution is supercritical and is obtained from the critical solution by adding a velocity discontinuity across the tributary mouth AB.

The basic solution does not now break down, however, when EÂx (or F̂िY) is less than $\frac{1}{4} \pi$, since such a vertex is not over-stressed when the wall is perfectly rough (Hill, I954). Instead we have to go over to another type of solution when one or other (or both )of these angles become zero. This occurs when $\psi=\pi$ or $\theta=\frac{1}{2} \pi$; in fact, since $\psi-\theta \leqslant \frac{1}{2} \pi$ the first condition can only occur if the latter also applies. In other words, the deformation can only spread upstream along the inner wall if it also spreads down-stream along this wall. The form of the slip-line field when the deformation spreads down-stream is shown in Figure 12 (a) and when it spreads in both directions in Figure $12(b)$. The domains of validity of these two solutions are regions $\mathrm{RB}$ and $\mathrm{RC}$ respectively in the $(\nu, \lambda)$ diagram (Fig. I I ).

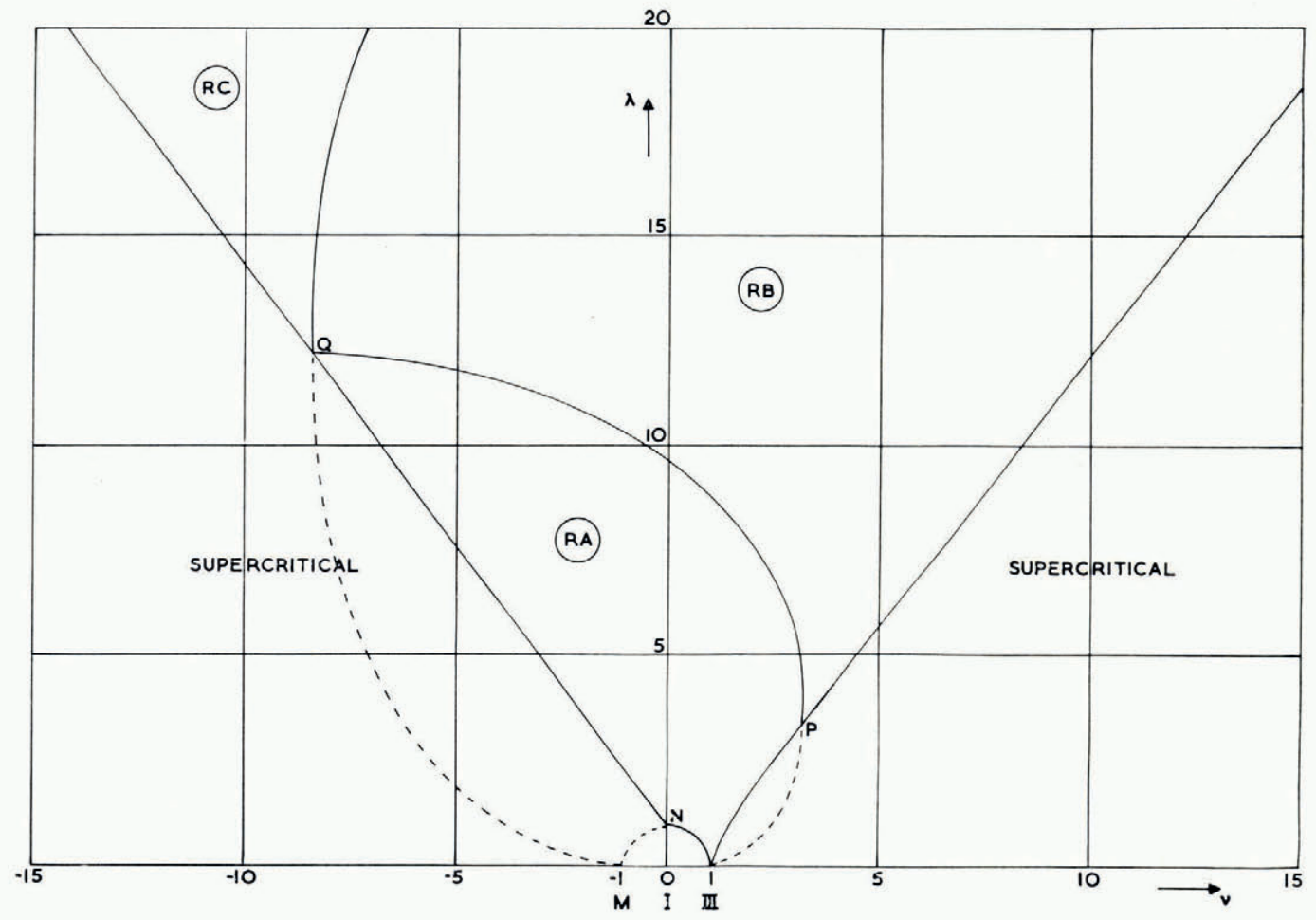

Fig. II. Nomograph for single tributary with rough walls. Solutions valid in regions RA, RB and RC are shown in Figures IO, $I_{2}(a)$ and $I 2(b)$, respectively.

\section{(vi) Right-angle junction with rough walls}

If we make the same specialization as in (iv) above, i.e. $\delta=\frac{1}{2} \pi$, the domains of validity of the three types of solution can be shown in a $\left(d / h, U_{\mathrm{I}} / U_{2}\right)$ diagram (Fig. $\left.9(\mathrm{~b})\right)$. The general form of this diagram is similar to that for smooth boundaries, although the basic field (RA) is valid for a rather larger range of values of $d / h$ than the corresponding field for smooth walls (sA). Also the solutions now become critical at a rather lower value of $U_{1} / U_{2}(\approx 0.7$ compared with unity). 
(vii) An example

Solutions for a particular example of a right-angled junction are shown in Figure 13 . The ratio $\lambda=d / h=2.5$, whilst $U_{1} / U_{2}=0.5$ so that $\nu=-\mathrm{I} .25$ from Equation (6). Using either Figure 5 or 9 (a) we see that this confluence is critical if we assume the walls are smooth, but Figure i $\mathrm{I}$ or 9 (b) indicates that it is supercritical if the walls are rough. In the first case there will be a slip-line but no velocity discontinuity across the tributary entrance, in the second case there will be both. The slip-line field solutions for these two conditions are shown in Figures I $_{3}(\mathrm{a})$ and (b), together with some typical stream-lines. The direction of the streamline through any point is given by the vector from the origin to the image point in the hodograph diagram. Stream-lines are hence very easily plotted graphically using the hodograph diagram (for further details see Prager ( I 959)).

The hodograph diagram for the rough-walled case is shown in Figure I3(c), whilst the magnitude and directions of the principal strain-rates at some representative points are shown in Figure I $_{3}(\mathrm{~d})$. The magnitude of the principal strain-rates $\pm \gamma$ can be conveniently evaluated from the expression (Green, 1954)

$$
\gamma=\frac{\mathrm{I}}{2}\left(\frac{S^{\prime}}{S}-\frac{R^{\prime}}{R}\right)
$$

where $R, S, R^{\prime}, S^{\prime}$ are the radii of curvature of the $\alpha-, \beta-, \alpha^{\prime}-, \beta^{\prime}$-curves respectively. In the centred fan region $\mathrm{ABF}, \gamma$ is inversely proportional to the radial distance from the vertex $\mathrm{B}$, and theoretically infinite actually at this vertex.

Figure I3(e) shows curves (dashed) of constant pressure $p$ through nodal points of $25^{\circ}$ angular separation. In order to keep the deformation one of plane strain the compressive stress normal to the flow planes must be equal to $p$, the all-round hydrostatic pressure (cf.

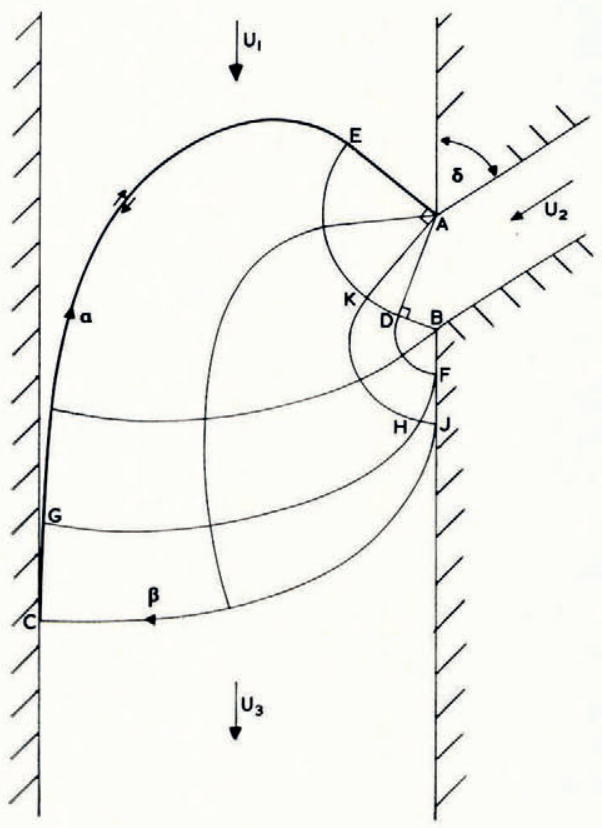

(a)

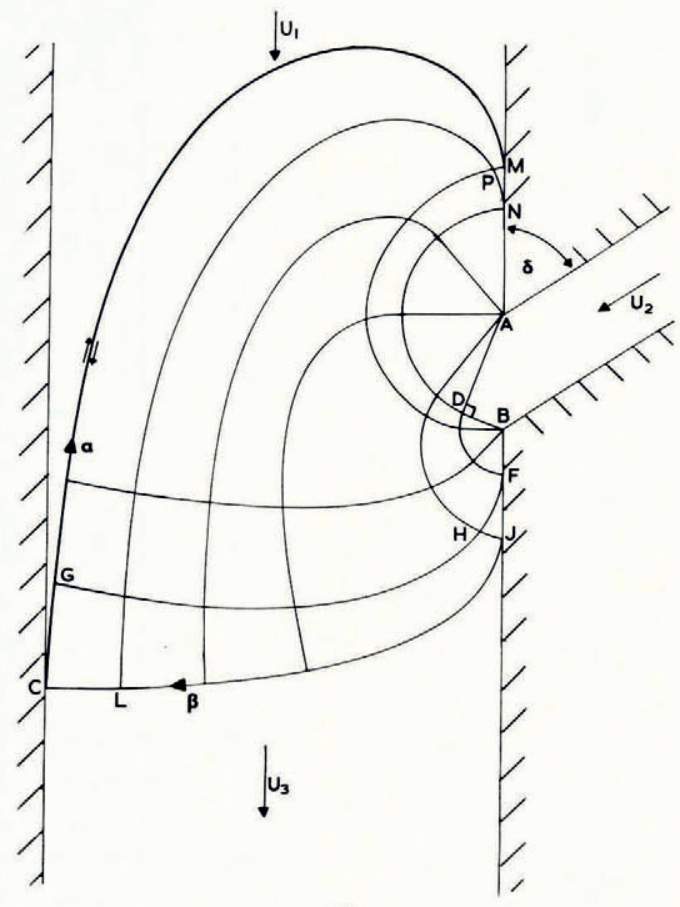

(b)

Fig. 12. Slip-line fields of solutions valid in regions $(a)_{-}^{-} \mathrm{RB}$ and $(b)$ RC. 


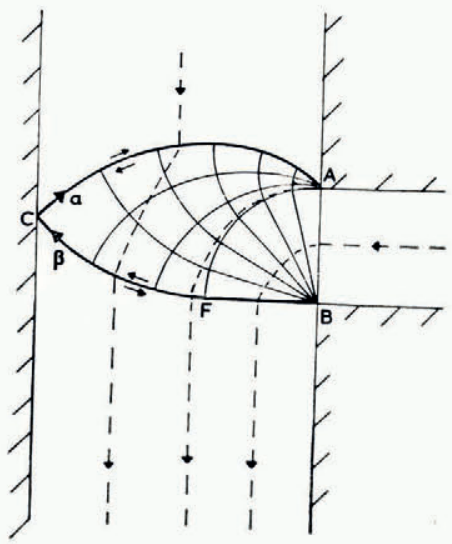

(a)

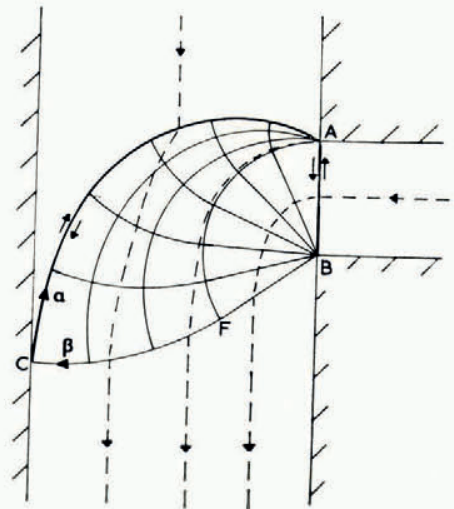

(b)

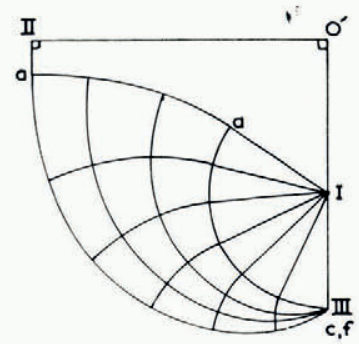

(c)

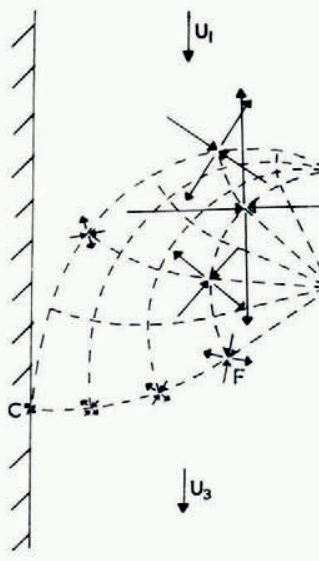

(d)

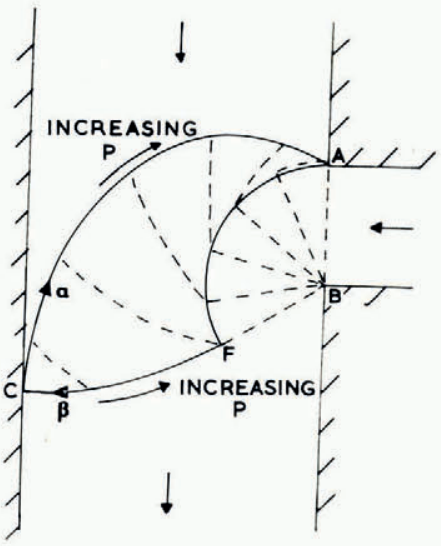

$(e)$

Fig. 13. An example of a $\mathbf{T}$-junction $\left(\beta=90^{\circ}\right)$ with $\lambda=d / h=2.5, U_{1} / U_{2}=0.5$. (a) slip-line field for smooth walls, $(b)$ slip-line field for rough walls, $(c)$ hodograph for rough walls, $(d)$ principal strain-rates (rough walls), $(e)$ constant pressure contours (rough walls). 
Hill, I 950, chapter 6). In going from one nodal point to the next in Figure I $_{3}$ (e) this pressure changes by $2 k \Delta \alpha$, where $\Delta \alpha=0.436$ which is $25^{\circ}$ in radians. This follows from Hencky's relations, Equations (I). Now just such a change in normal stress would occur if the thickness of the ice above the flow plane in question differed by an amount $2 h_{0} \Delta \alpha$ (where $h_{0}=k / \rho g$, $\rho$ being the density, $g$ the acceleration due to gravity) between these two points. Thus, the way in which $p$ varies throughout the deformation zone reflects the variation in surface height throughout the confluence zone. In particular, the constant pressure curves in Figure I $3(\mathrm{e})$ correspond to contours on the glacier surface.

This argument of course assumes that the deformation is, in fact, plane strain. It would be highly fortuitous, however, if the local accumulation/ablation distributions were such that the surface topography as predicted above represented a steady-state situation. Nevertheless, this way of identifying the constant-pressure curves of the slip-line field solution with surface contours at least gives some indication of the overall shape, position and magnitude of the surface disturbance at a confluence. In any case it is not possible to do any better without recourse to a three dimensional analysis.

An alternative method of obtaining a varying normal stress over these planes is to superimpose a secondary flow in each cross-section of the glacier. The type of secondary flow envisaged is shown in Figure 23 with reference to the deformation at a $\mathbf{Y}$-junction. As will be described in section 5 (iv) there is some field evidence for just such a flow pattern. Due to the nonlinearity of the governing equations we cannot, of course, quantitatively superimpose two velocity fields, rather these considerations only indicate qualitatively the possible nature of the actual three-dimensional flow.

The bulges which actually occur at the confluence of two glaciers are typically $20-30 \mathrm{~m}$ in height. This value is rather less than is predicted from identifying surface contours with the constant pressure curves of the slip-line solution. For example, if we take $k \approx \mathrm{I}$ bar,

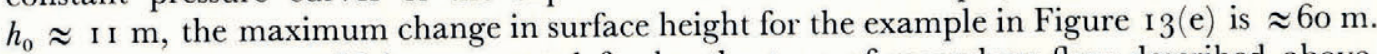
This discrepancy would be accounted for by the type of secondary flow described above, since this tends to thin the ice in regions where $p$ is large but to thicken it correspondingly where $p$ is small.

\section{INTERFERENCE BETWEEN TRIBUTARIES}

In this section we consider the problem of two tributaries entering a main stream, one on each side of the channel. If the entry regions are sufficiently far apart the solution is obtained simply by considering each confluence separately and constructing two separate deformation zones as described in the previous section. However, if the relative separation is small, the two slip-line fields would overlap and there must, therefore, be some interference between the two deformation zones.

The slip-line field and hodograph solutions to this problem are shown in Figure 14. The solution has five degrees of freedom: the angles $\theta, \psi, \theta^{\prime}, \psi^{\prime}$ and the inclination of the slip-lines at $\mathrm{c}$ to the main channel direction. These five angles are to be chosen so that the five defining quantities $d / h, d / h^{\prime}$, the relative velocity of the two tributaries to the upper main-stream flow and the eccentricity $e$ (as defined in Figure I $_{4}(\mathrm{a})$ ) take specified values. Due to the larger number of variables involved no attempt has been made to construct a nomograph corresponding to Figures 5 and I I for a single tributary.

The analysis is very much simplified, however, if the confluence is symmetric $\left(\delta=\delta^{\prime}\right.$, $\left.U_{2} / U_{2}^{\prime}, h=h^{\prime}\right)$ with zero eccentricity. In this case the slip-line field is symmetrical about the mid-line of the main-stream. The slip-lines meet this line at $\mathrm{c}$ and at an angle of $45^{\circ}$. We need, therefore, only consider one half of the solution and apply the analysis of the previous section for a single tributary but with $d$ replaced by $\frac{1}{2} d$.

It is to be noted that the solution of Figure 14 is valid for both types of frictional condition on the valley walls (smooth or rough) provided none of the postulated rigid vertices has 
included angle less than $45^{\circ}$ (in this case the smooth wall solution must be modified as in the previous section). Figure i 4 , of course, only shows the "basic solution" and will not cover all possible geometries and velocity conditions. It can, however, be easily extended on the same lines as for the single tributary.

Consider now the effect of increasing the eccentricity $e$, whilst keeping the other defining parameters fixed. As $e$ increases the direction of the $\alpha$-line at c (Fig. I4) approaches the vertical. At this critical point $\left(e=e_{1}\right.$ say) the magnitude of the velocity discontinuity on the

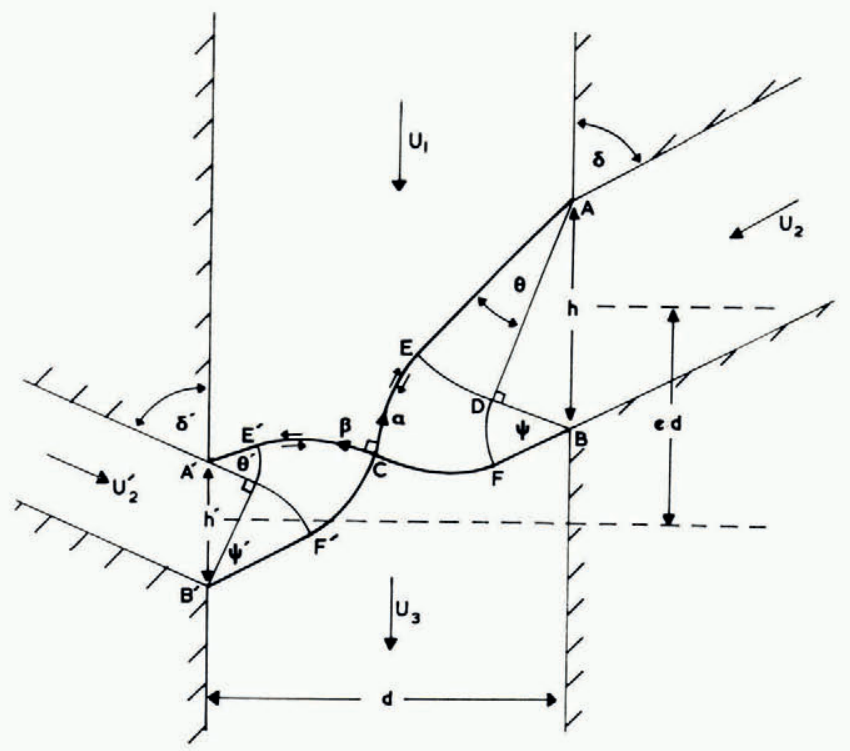

(a)

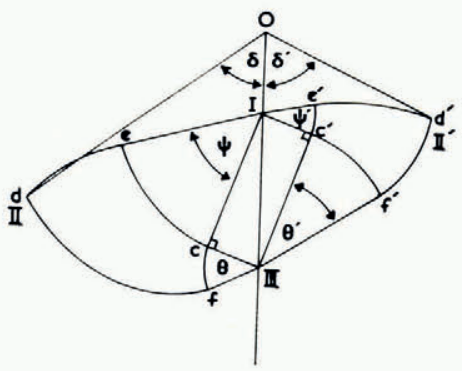

(b)

Fig. I4. Basic double tributary solution $\left(e \leqslant e_{\mathrm{I}}\right)$ (a) slip-line field, (b) hodograph.

$\alpha$-line has increased to $\left(U_{3}-U_{1}\right)$ whilst that on the corresponding $\beta$-line $\mathrm{A}^{\prime} \mathrm{E}^{\prime} \mathrm{CFB}$ has decreased to zero. For $e>e_{1}$ the solution cannot be of the type shown in Figure $1_{4}$ since the velocity discontinuity along the $\beta$-line would have to be of the opposite sign and would involve a negative work rate. Instead the solution is as shown in Figure 15 . The two deforming regions are exactly the same as when $e=e_{1}$ but are now relatively displaced and joined by a single straight slip-line $\mathrm{Cc}^{\prime}$, with velocity discontinuity $\left(U_{3}-U_{1}\right)$ separating two rigid regions.

In this way we can postulate solutions of this form for all $e>e_{1}$. However, we can find solutions, as discussed at the beginning of this section, consisting of two completely separate, 
non-overlapping deforming regions. It would thus appear that we have two completely different possible solutions. This paradox is resolved by appealing to the uniqueness and bound theorems of rigid/plasticity theory (Hill, I95I). In the present context these enable us to say that the true solution is the one involving the smaller total rate of energy dissipation. The other solution will be invalid because the material in part of the postulated rigid regions will, in fact, deform plastically. Thus the solution in Figure 15 will only be valid for a finite range of eccentricities $e_{1} \leqslant e \leqslant e_{2}$ say and the solution consisting of two unconnected deforming zones

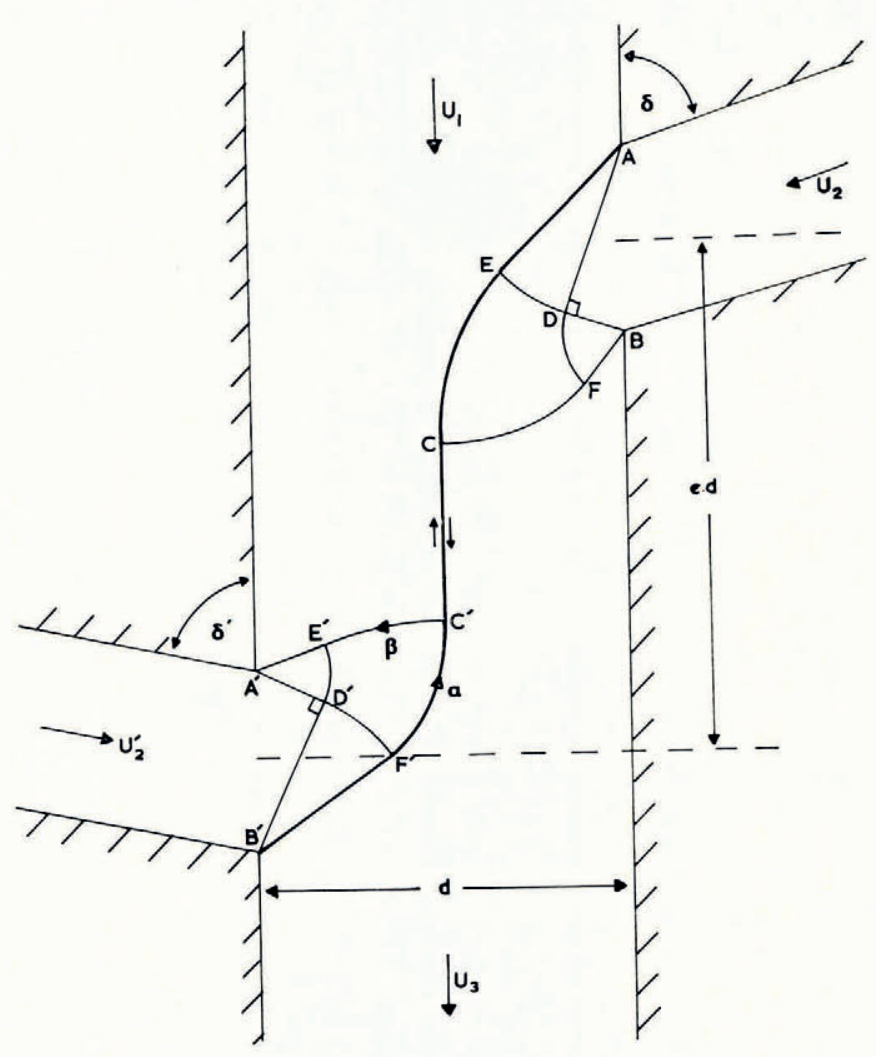

Fig. I5. Double tributary solution for $e_{1} \leqslant e \leqslant e_{2}$.

is valid for $e \geqslant e_{2}$. The value of the critical eccentricity $e_{2}$ is obtained by equating the total rates of dissipation in the two solutions.

The evaluation of these two critical eccentricities is extremely complicated in general, and we are here content with obtaining typical values which relate to the corresponding extrusion problem with equal orifices (Duncan and others, 1966). The extrusion situation is much simplified since $\psi^{\prime}=\theta, \theta^{\prime}=\psi$ and the radii of the centred fans in each of the two deforming zones are equal. The critical eccentricities are obtained by using approximate analytical expressions for the extrusion pressures giving $e_{1} \approx 1$ and $e_{2} \approx 2$; these values being (approximately) the same whether the walls are assumed rough or smooth. 


\section{Confluence of two main streams}

\section{(i) Simplest case - two straight velocity discontinuities}

Consider now the junction of two main streams as shown in Figure 16 . To reduce the number of defining parameters, we will only consider geometries in which the lines across the mouths of the two converging streams are perpendicular to the valley walls, so that cîx and BÂY in Figure $\mathbf{r} 6$ are right angles. The problem is completely posed if we know the ratios $d_{2} / d_{1}, U_{2} / U_{\mathrm{I}}$ and the angles $\delta_{\mathrm{I}}$ and $\delta_{2} . d_{3}$ and $U_{3}$ are then determined by geometry and mass conservation respectively:

$$
\begin{gathered}
d_{3}=d_{1} \cos \delta_{1}+d_{2} \cos \delta_{2}, \\
U_{3} d_{3}=U_{1} d_{1}+U_{2} d_{2} .
\end{gathered}
$$

For certain values of these parameters the deformation is particularly simple, consisting of just two velocity discontinuities (shear bands) across the mouths of the two upper streams (Fig. I6(a)). From the corresponding velocity diagram (Fig. I6(b)), we see that this solution is valid only when the velocity ratio is

$$
U_{2} / U_{1}=\cos \delta_{2} / \cos \delta_{1}
$$

\section{(ii) Symmetric junction}

For more general velocity ratios the situation is rather more complicated and it is convenient first to consider junctions with symmetric geometries $\left(d_{1}=d_{i}, \delta_{1}=\delta_{2}\right)$. The simple solution of Figure $\mathrm{I} 6$ is only valid for a symmetric junction if $U_{2} / U_{1}=\mathrm{I}$. We now consider the effect of varying this ratio and without loss of generality we may suppose $U_{2} / U_{1} \geqslant \mathrm{I}$.

A solution to this problem is shown in Figure 17 with the associated hodograph. The slipline field $\mathrm{BAD}$ is a centred fan whilst $\mathrm{ADE}$ has a singularity at $\mathrm{A}$ and is defined by the circular arc $\mathrm{AD}, \mathrm{CE}$ is a straight velocity discontinuity on either side of which the material moves rigidly.

For symmetric junctions the conservation of mass condition, Equation (9) reduces to

$$
U_{\mathrm{I}}+U_{2}=2 U_{3} \cos \delta \text {. }
$$

From this condition it follows by simple trigonometry that the speeds of the two upper streams relative to the lower one $\left(L_{1}\right.$ and $L_{2}$ in Figure $\left.{ }_{1} 7(\mathrm{c})\right)$ are both equal to $\left(U_{3}^{2}-U_{1} U_{2}\right)^{\frac{1}{2}}$, which is the value of the velocity discontinuity along AEc. It follows from this result and the fact that $d_{1}=d_{2}$, that the slip-line and hodograph nets are geometrically similar.

If we produce II $Q$ to meet $\mathrm{O}$ III at $\mathrm{T}$ in Figure $\mathrm{I}_{7}(\mathrm{~b})$, we see that $\mathrm{T}$ must lie below III and hence $U_{3} \cos \delta<U_{2}$. From Equation (I I) it follows that $U_{2} / U_{\mathrm{I}}$ is indeed greater than unity. Thus, the straight (and weaker) velocity discontinuity occurs across the mouth of the stream with the greater velocity.

As $U_{2} / U_{\mathrm{I}}$ increases a critical point is reached at which $\mathrm{E}$ and c coincide. Also, since the slip-line field and hodograph are geometrically similar, II and $\mathrm{Q}$ also coincide, so that the velocity discontinuity on $\mathrm{AB}$ vanishes concurrently with the length CE. For values of $U_{2} / U_{\mathrm{I}}$ greater than this critical value the solution is as shown in Figure $\mathrm{I} 8$, it being very similar to the basic solution for a single tributary. There is now no velocity discontinuity across the mouth of the 2-stream, instead that along AEc is reflected back (though with diminished magnitude) along CDB. Again the hodograph (Fig. I8(b)) is similar to the slip-line field.

These solutions are valid for all frictional conditions provided all rigid vertices are greater than $45^{\circ}$, otherwise the solution for smooth walls must be modified as previously.

The values at which $\left(U_{2} / U_{1}\right)$ becomes critical and the solution goes over from that of Figure 17 to that of Figure 18 is shown plotted against $\delta$ in Figure 19 . As $\delta$ increases from zero, $\left(U_{2} / U_{\mathrm{I}}\right)_{\text {crit }}$ increases from unity and tends to infinity as $\delta \rightarrow 60^{\circ}$. At this angle $\psi=0$ and $\mathrm{C}$ and $\mathrm{D}$ coincide (Fig. I $7(\mathrm{a})$ ) and for $\delta>60^{\circ}$ the solution is always of the type shown in Figure 17. 

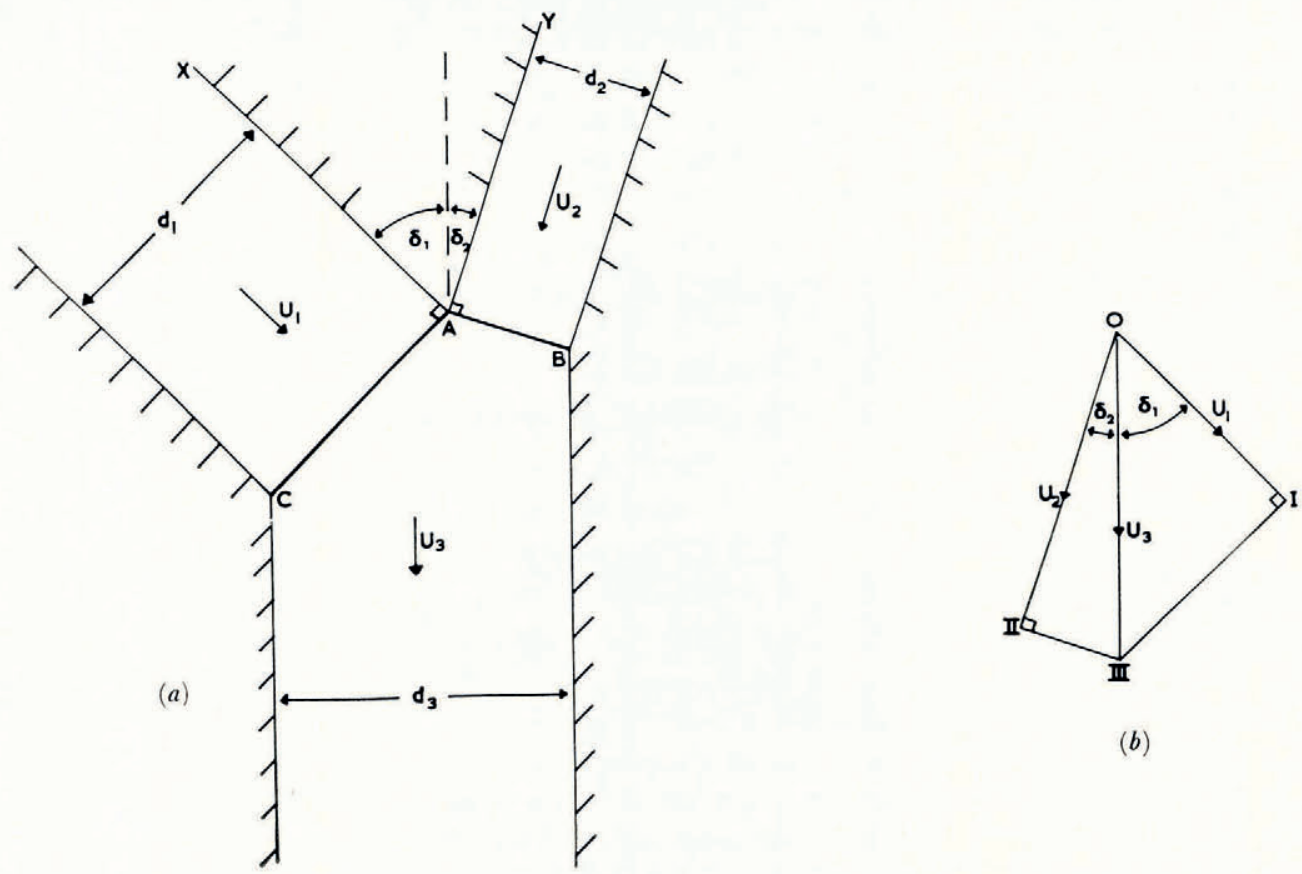

(b)

Fig. 16. Confluence of two main streams ( $\mathbf{Y}$-junction). The simplest solution consisting of just two velocity discontinuities (shear bands) $\mathrm{AB}$ and $\mathrm{AC} .($ a) slip-line field, (b) hodograph.

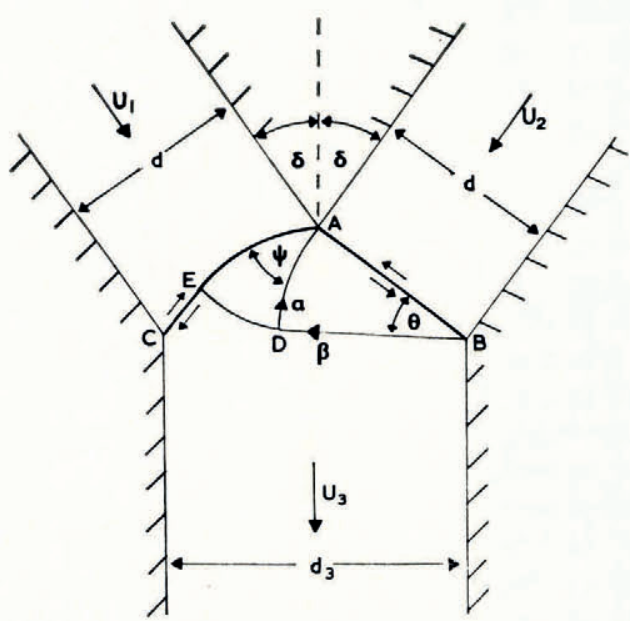

(a)

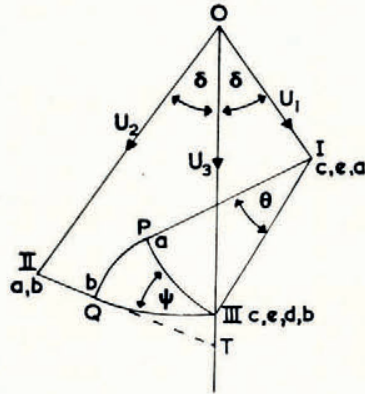

(b)

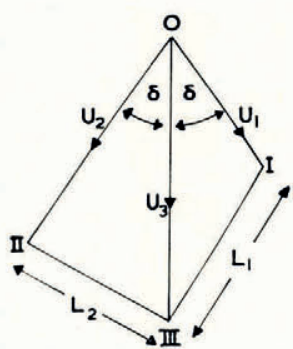

(c)

Fig. 17. Solution for symmetric $\mathbf{Y}$-junction for $I \leqslant U_{2} / U_{1} \leqslant\left(U_{2} / U_{1}\right)$ crit. (a) slip-line field, (b) hodograph, (c) velocity vectors. 
(iii) Asymmetrical junction

We now consider the more general situation of an asymmetrical junction $\left(\delta_{1} \neq \delta_{2}\right.$, $\left.d_{1} \neq d_{2}\right)$. The basic solution is shown in Figure 20 and is valid for a range of values of $U_{2} / U_{1} \geqslant \cos \delta_{2} / \cos \delta_{1}$. This solution differs from the corresponding solution for a symmetric junction (Fig. I7) as in general the slip-line field and hodograph are not now totally similar in that the lengths EC and $Q \mathrm{II}$ are not proportional. From the general mass conservation condition (9) it is easy to show that the speeds of the two upper streams relative to the lower stream $\left(L_{1}\right.$ and $L_{2}$ in Figure $\left.20(\mathrm{c})\right)$ are related by

so that

$$
\left(d_{1}^{2} L_{1}^{2}-d_{2}^{2} L_{2}^{2}\right)=U_{3}^{2}\left(d_{1}^{2} \sin ^{2} \delta_{1}-d_{2}^{2} \sin ^{2} \delta_{2}\right),
$$

$$
L_{1} / d_{2}>\text { or }<L_{2} / d_{1} \quad \text { as } \quad d_{1} \sin \delta_{1}>\text { or }<d_{2} \sin \delta_{2} \text {. }
$$

Thus the slip-line and hodograph diagrams are completely similar if and only if $d_{\mathrm{I}} \sin \delta_{\mathrm{I}}=d_{2} \sin \delta_{2}$; i.e. if $\mathrm{BC}$ is perpendicular to the walls of the lower channel.
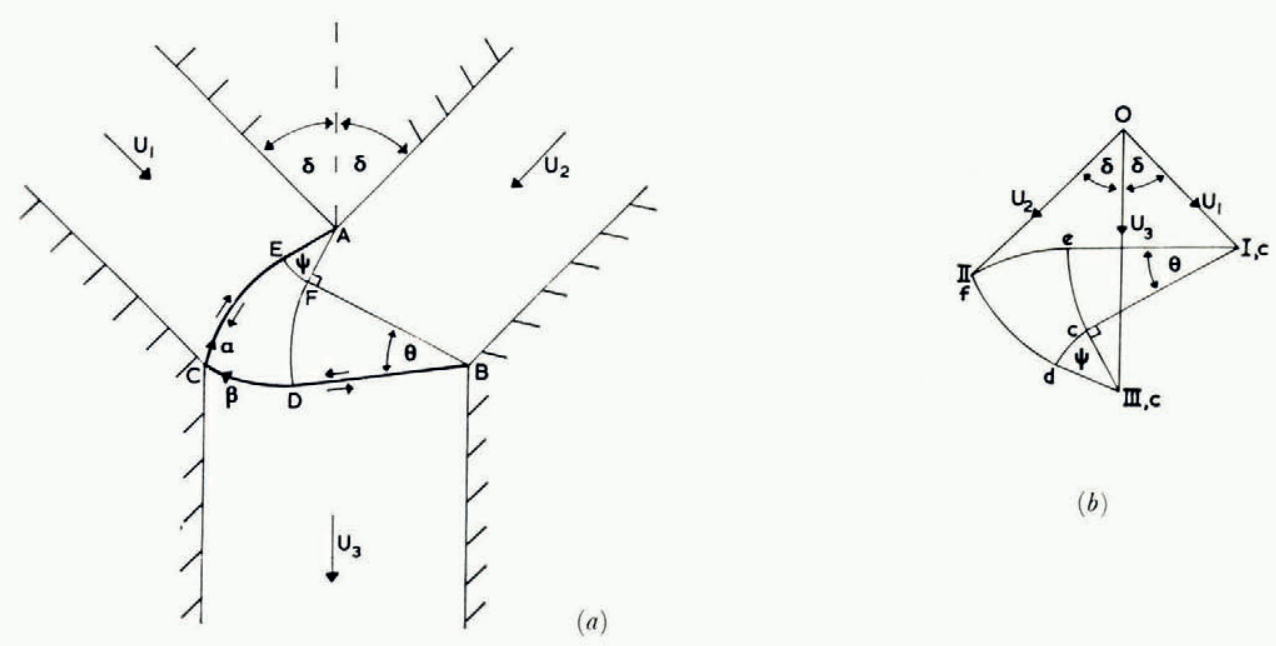

Fig. 18. Solution for symmetric $\mathbf{Y}_{-j}$ junction for $U_{2} / U_{1} \geqslant\left(U_{2} / U_{1}\right)$ crit. (a) slip-line field, (b) hodograph.

Consider now the effect of increasing $U_{2} / U_{1}$ until the solution breaks down for some reason: we distinguish three cases depending on the relative positions of $\mathrm{A}, \mathrm{B}$ and $\mathrm{C}$.

(a) If $\mathrm{BC}$ is perpendicular to the lower channel walls, CE (Fig. 2O(a)) and Q II (Fig. 2O(b)), the velocity discontinuity on $\mathrm{AB}$, vanish together as in the symmetric case since the slip-line and hodograph diagrams are totally similar. For larger values of $U_{2} / U_{1}$ we go over to a solution of the type shown in Figure 18 for a symmetric junction.

(b) If c lies below $\mathrm{B}$, then $L_{\mathrm{I}} / d_{2}>L_{2} / d_{1}$ from Inequality ( $\mathrm{I}_{3}$ ) and hence Q II vanishes before CE does. In this case we must go over to a field of the type shown in Figure $2 \mathrm{I}(\mathrm{a})$, where AEC is still a velocity discontinuity but AB is no longer a slip-line. This field remains valid until CE also vanishes and we then switch to the solution in Figure 18 as in (a) above.

(c) If $\mathrm{c}$ lies below $\mathrm{B}$, then $L_{\mathrm{I}} / d_{2}<L_{2} / d_{1}$ and this time the length GE vanishes first. When this happens the solution goes over to that shown in Figure $2 \mathrm{I}(\mathrm{b})$, which involves three velocity discontinuities. We again go over to the Figure 18 solution when $U_{2} / U_{\mathrm{I}}$ has increased to the point where $Q$ II also vanishes.

In principle we can, therefore, construct solutions to cover all possible velocity ratios. However, no attempt has been made to compute the various critical velocity ratios for the general asymmetrical junction due to the large number of independent parameters involved. 


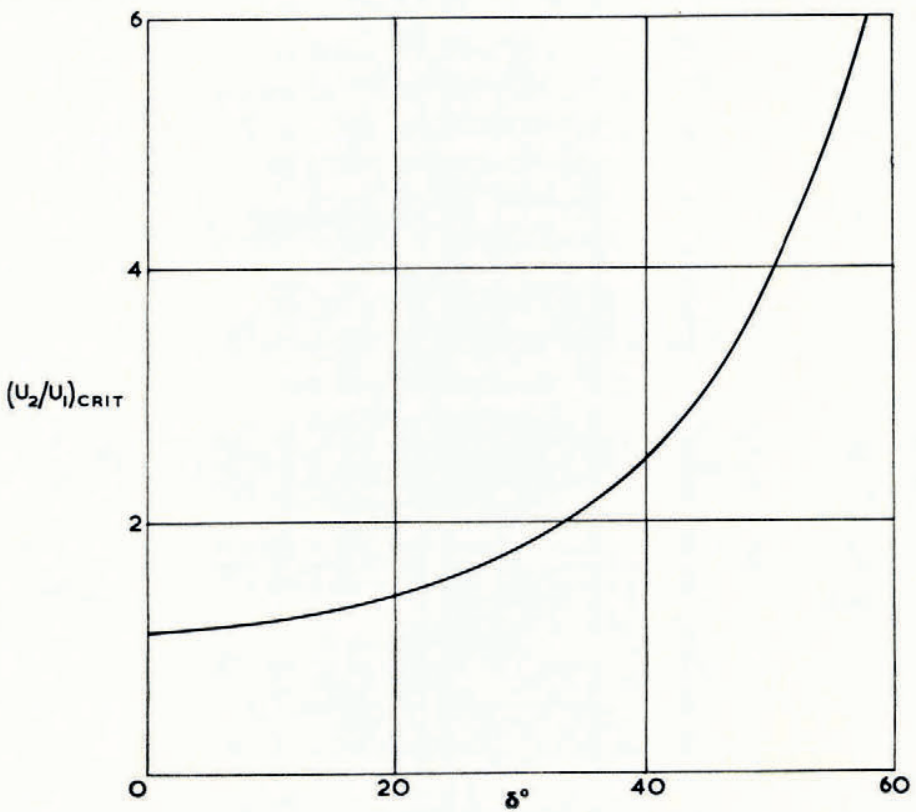

Fig. 19. Plot of $\left(U_{2} / U_{1}\right)$ crit. against $\delta$ for symmetric $\mathbf{Y}$-junction.

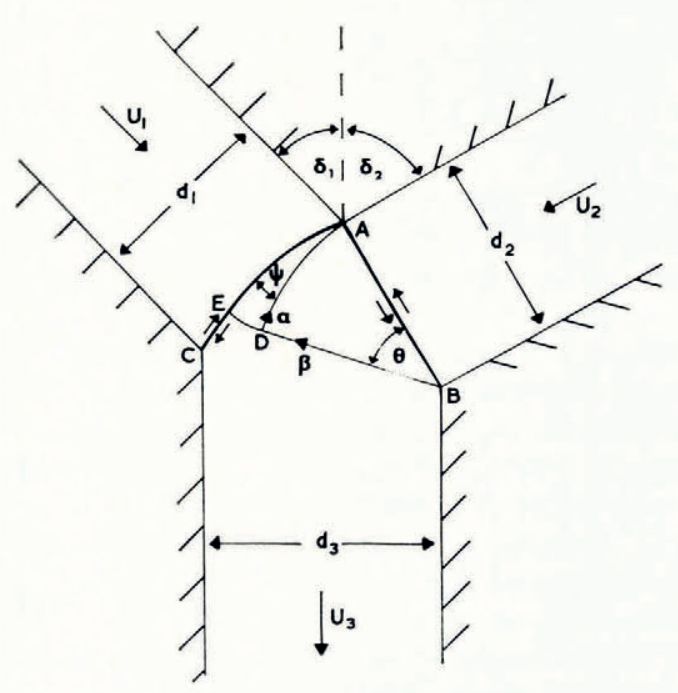

(a)

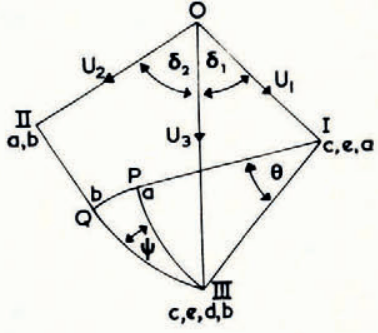

(b)

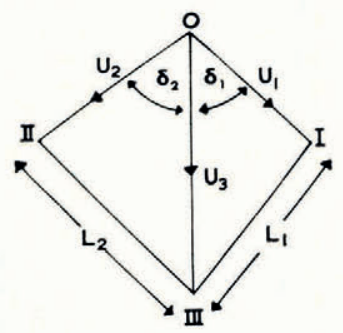

(c)

Fig. 20. Solution for asymmetric $\mathbf{Y}$-junction for $\cos \beta_{2} / \cos \beta_{1} \leqslant U_{2} / U_{1} \leqslant\left(U_{2} / U_{1}\right)$ crit. (a) slip-line field, (b)hodograph, (c) velocity vectors. 


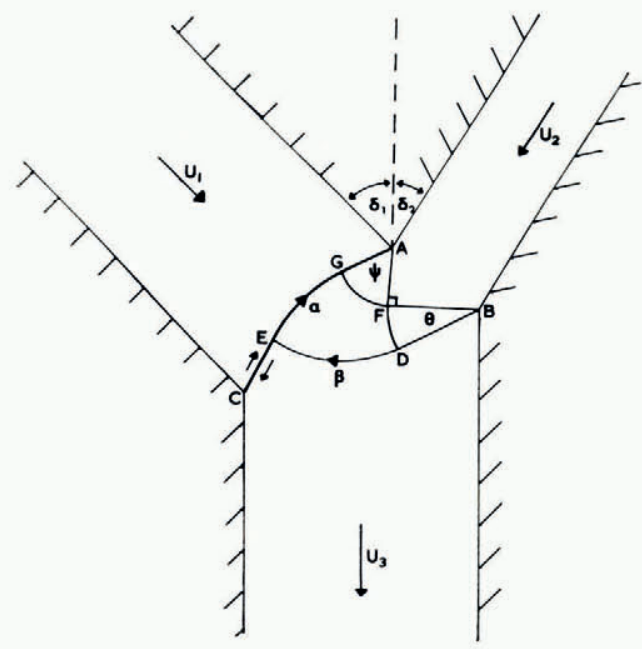

(a)

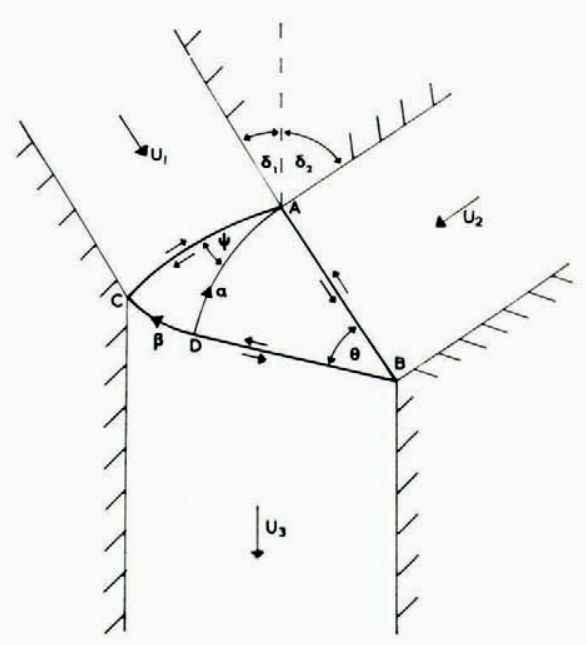

(b)

Fig. 2I. Intermediate slip-line field solutions for asymmetric $\mathbf{Y}$-junction, $\left(U_{2} / U_{1}\right) \geqslant\left(U_{2} / U_{\mathrm{I}}\right)$ crit. $(a)$ с below в, $($ b $)$ в below c.

(iv) An example

A sketch of the confluence zone of the north and central arms of the Kaskawulsh Glacier, Yukon Territory, Canada, is shown in Figure 22(a), together with the surface velocity vectors measured by Anderton (1967). The confluence is symmetric in that $\delta_{1} \approx \delta_{2} \approx 22^{\circ}$, but the widths of the two main streams are unequal, that of the north and central arms being $3 \mathrm{~km}$ and $3.5 \mathrm{~km}$, respectively. The corresponding theoretical solution is shown in Figure 22(b). The

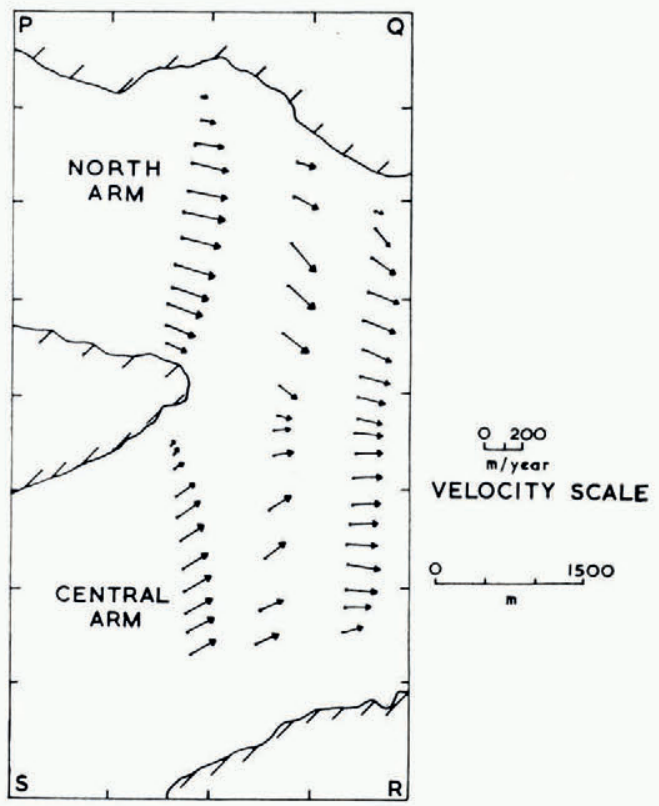

(a)

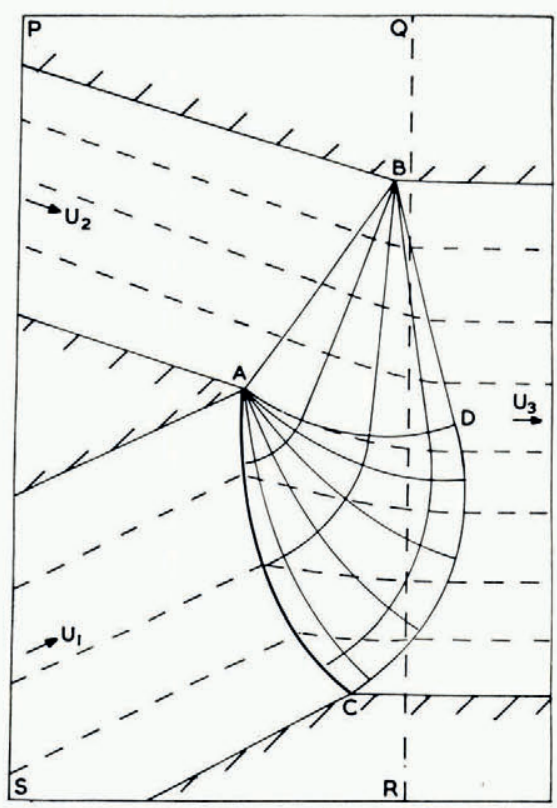

(b)

Fig. 22. (a) Field measurements of ice-flow vectors at confluence of north and central arms of Kaskawulsh Glacier, Yukon Territory, Canada (after Anderton, unpublished). (b) Slip- and stream-lines of ideal model. 
effective sides of the glacier are approximated by straight lines. The configuration differs from the type considered above in that the exit lines $(\mathrm{AB}, \mathrm{AC})$ of the two arms are not perpendicular to the valley walls. Nevertheless, the solution will be of the same form as those discussed above. The field shown is the critical case in which there is no velocity discontinuity along $\mathrm{AB}$ or CDB. From the hodograph diagram this solution is found to correspond to a velocity ratio $U_{2} / U_{\mathrm{I}}=\mathrm{I} \cdot 35$. This closely approximates the actual situation, since the ratio of both maxumim and mean velocity in these two channels is approximately I.4.

Some typical theoretical stream lines are shown in Figure 22(b). The actual flow directions converge markedly just below the confluence. This effect is not predicted in our theory. This phenomenon may be attributed (as is done by Anderton) to the speeding up of the ice in the region of the medial moraine as it is freed from the retarding influence of the valley walls. This effect would not be present in our model since the velocity is assumed uniform above the deforming zone.

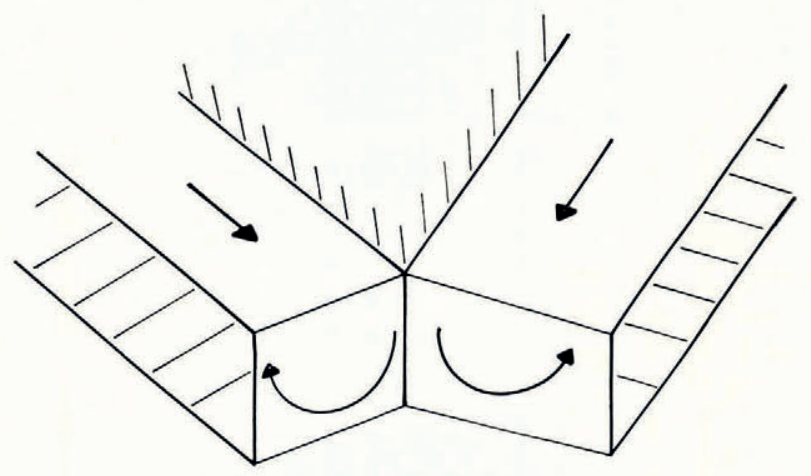

Fig. 23. Secondary flow in cross-sections at a $\mathbf{Y}$-junction.

Anderton did not find any trace of intense shear in the north arm but did find a confused shear zone in the central arm, which is consistent with one prediction that the deformation is close to being critical.

The measured direction and magnitude of the surface principal strain-rates are broadly in agreement with theory. Near the centre of each arm the measured principal compressive and tensile components of strain-rate in the surface are of equal magnitude, indicating a plane-strain deformation. Either side of the medial moraine, however, the compressive component is the larger whilst near the outer margin the tensile component dominates. The sum of the three principal strain-rates must be zero for an incompressible material so that the vertical principle strain-rate component is tensile at the medial moraine but compressive near the outer walls. Such a strain-rate field would be produced by the type of secondary flow shown in Figure 23 and previously discussed in section 3(vii).

\section{Acknowledgements}

Apart from the final writing up, this work was completed whilst I held an S.R.C. research grant at the University of Cambridge. I am very grateful to my supervisor, Dr R. Hill, for suggesting this problem to me.

\section{MS. received 4 September 1969}




\section{REFERENCES}

Allen, C. R., and others. 1960. Structure of the lower Blue Glacier, Washington, [by] C. R. Allen, W. B. Kamb, M. F. Meier and R. P. Sharp. Journal of Geology, Vol. 68, No. 6, p. 601-25.

Anderton, P. W. Unpublished. Structural glaciology of a glacier confluence, Kaskawulsh Glacier, Yukon Territory, Canada. [Ph.D. thesis, Ohio State University, r967.]

Berg, C. A. 1967 . The character of plane deformation fields in isotropic incompressible nonlinear viscous fluids. Fournal of Mathematics and Physics, Vol. 46, No. 4, p. 448-58.

Collins, I. F. I $968[\mathrm{a}]$. The algebraic-geometry of slip line fields with applications to boundary value problems. Proceedings of the Royal Society, Ser. A, Vol. 303 , No. 1474, p. 317-38.

Collins, I. F. I968[b]. Geometric properties of some slip-line fields for compression and extrusion. Fournal of the Mechanics and Physics of Solids, Vol. I6, No. 3, p. 1 $37-52$.

Duncan, J. L., and others. 1966 . Some experiments and theory for plane-strain side-extrusions, by J. L. Duncan, W. Johnson and A. Ovreset. Proceedings of the Institution of Mechanical Engineers (London), Vol. I80, Pt. 31 , p. $24 \mathrm{I}-49$.

Ewing, D. J. F. 1967. A series-method for constructing plastic slipline fields. Fournal of the Mechanics and Physics of Solids, Vol. ${ }_{15}$, No. 2, p. $105^{-1} 4$.

Ford, H., and Alexander, J. M. 1963 . Advanced mechanics of materials. London, Longmans, Green and Co., Ltd.

Green, A. P. I954. On the use of hodographs in problems of plane plastic strain. Journal of the Mechanics and Physics of Solids, Vol. 2, No. 2, p. 73-80.

Green, W. A. I 962 . Extrusion through smooth square dies of medium reduction. Fournal of the Mechanics and Physics of Solids, Vol. 10, No. 3, p. 225-33.

Hill, R. 1950. The mathematical theory of plasticity. Oxford, Clarendon Press.

Hill, R. 1951. On the state of stress in a plastic-rigid body at the yield point. Philosophical Magazine, Seventh Ser., Vol. 42, No. 331, p. 868-75.

Hill, R. I 954. On the limits set by plastic yielding to the intensity of singularities of stress. Fournal of the Mechanics and Physics of Solids, Vol. 2, No. 4, p. 278-85.

Johnson, W., and Kudo, H. I962. The mechanics of metal extrusion. Manchester, Manchester University Press.

Johnson, W., and Mellor, P. B. 1962 . Plasticity for mechanical engineers. Princeton, N.J., etc., Van Nostrand. Meier, M. F. 1960. Mode of flow of Saskatchewan Glacier, Alberta, Canada. U.S. Geological Survey. Professional
Paper 35.

Nye, J. F. 1951. The flow of glaciers and ice-sheets as a problem in plasticity. Proceedings of the Royal Society, Ser. A, Vol. 207, No. 1091, p. 554-72.

Nye, J. F. r953. The flow law of ice from measurements in glacier tunnels, laboratory experiments and the Jungfraufirn borehole experiment. Proceedings of the Royal Society, Ser. A, Vol. 219, No. 1 1 39, p. 477-89.

Nye, J. F. 1957. The distribution of stress and velocity in glaciers and ice-sheets. Proceedings of the Royal Society, Ser. A, Vol. 239, No. 1216, p. $113-33$.

Nye, J. F. I967. Plasticity solution for a glacier snout. Fournal of Glaciology, Vol. 6, No. 47, p. 695-7 I5.

Nye, J. F.. and Martin, P. C. S. I968. Glacial erosion. Union de Géodésie et Géophysique Internationale. Association Internationale d'Hydrologie Scientifique. Assemblée générale de Berne, 25 sept. 7 oct. 1967 . [Commission de Neiges et
Glaces] Repports Glaces.] Rapports et discussions, p. $78-86$.

Prager, W. 1953. A geometrical discussion of the slip-line field in plane plastic flow. Kungliga Tekniska Högskolans Handlingar (Stockholm), No. 65 .

Prager, W. 1959. An introduction to plasticity. Reading. Mass., Addison-Wesley Publishing Co., Inc.

Prager, W., and Hodge, P. G. I951. Theory of perfectly plastic solids. New York, John Wiley and Sons, Inc.

Sharp, R. P. 1948. The constitution of valley glaciers. Journal of Glaciology, Vol. I, No. 4, p. 182-89. 